\title{
The optimal choice of medication administration route regarding intravenous, intramuscular, and subcutaneous injection
}

This article was published in the following Dove Press journal:

Patient Preference and Adherence

2 July 2015

Number of times this article has been viewed

\author{
Jing-fen Jin' \\ Ling-ling $\mathrm{Zhu}^{2}$ \\ Meng Chen ${ }^{3}$ \\ Hui-min $X^{3}$ \\ Hua-fen Wang' \\ Xiu-qin Feng' \\ Xiu-ping Zhu ${ }^{3}$ \\ Quan Zhou ${ }^{3}$
}

'Division of Nursing, ${ }^{2}$ VIP Care Ward, Division of Nursing, ${ }^{3}$ Department of Pharmacy, The Second Affiliated Hospital, School of Medicine, Zhejiang University, Hangzhou, People's

Republic of China
Correspondence: Quan Zhou Department of Pharmacy, The Second Affiliated Hospital, School of Medicine, Zhejiang University, Jiefang Road No 88, Shangcheng District, Hangzhou 310009 , Zhejiang Province, People's Republic of China

Tel +86 57| 877846 I5

Fax +86 57। 87022776

Email zhouquan 142602@zju.edu.cn
Background: Intravenous (IV), intramuscular (IM), and subcutaneous (SC) are the three most frequently used injection routes in medication administration. Comparative studies of SC versus IV, IM versus IV, or IM versus SC have been sporadically conducted, and some new findings are completely different from the dosage recommendation as described in prescribing information. However, clinicians may still be ignorant of such new evidence-based findings when choosing treatment methods.

Methods: A literature search was performed using PubMed, MEDLINE, and Web of Sciences ${ }^{\mathrm{TM}}$ Core Collection to analyze the advantages and disadvantages of SC, IV, and IM administration in head-to-head comparative studies.

Results: "SC better than IV" involves trastuzumab, rituximab, antitumor necrosis factor medications, bortezomib, amifostine, recombinant human granulocyte-macrophage colony-stimulating factor, granulocyte colony-stimulating factor, recombinant interleukin-2, immunoglobulin, epoetin alfa, heparin, and opioids. "IV better than SC" involves ketamine, vitamin K1, and abatacept. With respect to insulin and ketamine, whether IV has advantages over SC is determined by specific clinical circumstances. "IM better than IV" involves epinephrine, hepatitis B immunoglobulin, pegaspargase, and some antibiotics. "IV better than IM" involves ketamine, morphine, and antivenom. "IM better than SC" involves epinephrine. "SC better than IM" involves interferon-beta-1a, methotrexate, human chorionic gonadotropin, hepatitis B immunoglobulin, hydrocortisone, and morphine. Safety, efficacy, patient preference, and pharmacoeconomics are four principles governing the choice of injection route. Safety and efficacy must be the preferred principles to be considered (eg, epinephrine should be given intramuscularly during an episode of systemic anaphylaxis). If the safety and efficacy of two injection routes are equivalent, clinicians should consider more about patient preference and pharmacoeconomics because patient preference will ensure optimal treatment adherence and ultimately improve patient experience or satisfaction, while pharmacoeconomic concern will help alleviate nurse shortages and reduce overall health care costs. Besides the principles, the following detailed factors might affect the decision: patient characteristics-related factors (body mass index, age, sex, medical status [eg, renal impairment, comorbidities], personal attitudes toward safety and convenience, past experience, perception of current disease status, health literacy, and socioeconomic status), medication administration-related factors (anatomical site of injection, dose, frequency, formulation characteristics, administration time, indication, flexibility in the route of administration), and health care staff/institution-related factors (knowledge, human resources).

Conclusion: This updated review of findings of comparative studies of different injection routes will enrich the knowledge of safe, efficacious, economic, and patient preference-oriented medication administration as well as catching research opportunities in clinical nursing practice.

Keywords: administration route, dosage and administration, efficacy, medication safety, patient preference, pharmacoeconomic 


\section{Introduction}

Injections are among the most common health care procedures throughout the world, with at least 16 billion administered in developing and transitional countries each year. ${ }^{1}$ Intravenous (IV), subcutaneous (SC), and intramuscular (IM) are three most frequently used injection routes in medication administration. IV injection is the introduction of a medication into the veins using a needle, and it is used when rapid absorption is called for, when fluid cannot be taken by mouth, or when the medication to be administered is too irritating to be injected into the skin or muscles. SC injection is administered as a bolus into the subcutis. IM injection is the technique used to deliver a medication deep into the muscles, allowing the medication to be absorbed into the bloodstream quickly. Prescribing information for some medications notes that they can be injected via one or more routes (eg, epinephrine can be delivered by IV, IM, or SC route), while prescribing information for the majority of injectable medications only describes one injection route.

On December 11, 2013, National Health and Family Planning Commission of the People's Republic of China advocated a principle of rational use of medicines, that is, "Injection is not suggested for patients when oral formulations would be more appropriate and IV infusion is not recommended when IM would be possible". ${ }^{2}$ A questionnaire-based survey by Plumb et al in 2013 demonstrated that only $74 \%$ of junior doctors selected the correct IM route of epinephrine in management of anaphylaxis. ${ }^{3}$ In the first half-year of 2014, The Second Affiliated Hospital of Zhejiang University (SAHZU), People's Republic of China, experienced a fatal adverse event which was partially associated with inappropriate injection route (ie, physician ordered SC epinephrine instead of IM epinephrine in anaphylaxis treatment, which may have delayed epinephrine absorption). SAHZU revised the standard operation procedure for anaphylaxis treatment in which IM was listed as the unique injection route of epinephrine. The epinephrine case in SAHZU together with the survey by Plumb et al has raised concerns about lack of knowledge concerning the recognition and management of anaphylaxis among front-line medical staff.

There is little literature reviewing the advantages and disadvantages of IV, IM, and SC administration. Gabriel reviewed the access of IV versus SC for palliative care patients. ${ }^{4}$ Stoner et al conducted a systematic review of randomized controlled trials investigating patient preference for SC versus IV administration and concluded that patients preferred SC over IV delivery. ${ }^{5}$ Comparative studies of SC versus IV, IM versus IV, or IM versus SC were sporadically reported, and many new findings cropped up. For example, Reggia et al analyzed the switch to SC administration of abatacept from IV administration in patients with rheumatoid arthritis and observed that SC abatacept showed a risk of relapse in $27 \%$ of cases and return to the IV administration quickly reinstated disease control (ie, IV is better than SC). ${ }^{6}$ The findings of Reggia et al challenge the viewpoint that the SC route is generally preferred over IV route because it enables at-home injection, improves quality of life, and reduces health care costs. ${ }^{4,5,7}$ Meanwhile, some findings are completely different from the dosage recommendation in prescribing information. Clinicians may still be ignorant of such information when choosing administration route.

In this paper, we investigate this issue in-depth and present an updated review, with the intention of improving the readers' knowledge of rational use of injectable medications.

\section{Methods}

Potentially relevant literature during 1980 to February 2015 was identified by performing searches in the PubMed, MEDLINE, and Web of Sciences ${ }^{\mathrm{TM}}$ Core Collection with an English-language filter. For PubMed, the search query was to identify each paper with the title containing "(intramuscular and intravenous)" or "(intramuscular and subcutaneous)" or "(subcutaneous and intravenous)", with a filter of "species: human". For Web of Sciences, the search string was "title: (intramuscular and intravenous) or title: (intramuscular and subcutaneous) or title: (subcutaneous and intravenous)", with a document-type filter excluding proceeding papers, meeting abstracts, notes, correction, correction addition, and book review. For MEDLINE, the search string was "title: (intramuscular and intravenous) or title: (intramuscular and subcutaneous) or title: (subcutaneous and intravenous)", refined by "MeSH headings: (humans)".

Two reviewers (MC and HMX) independently searched the literature and screened the relevant studies. The flowchart showing selection of literature is presented in Figure 1. Each reviewer was blinded to the other reviewer during the process of data extraction. In the event of disagreement between the two reviewers, a third reviewer (QZ) was consulted. Sixty-five original papers on the comparison of injection route were finally included based on the inclusion/ exclusion criteria. Valuable information was summarized by data interpretation.

Reviewers (MC, HMX, and QZ) listed all medications exhibiting obvious advantages of one route over the other route, and then focused on these medications and performed 


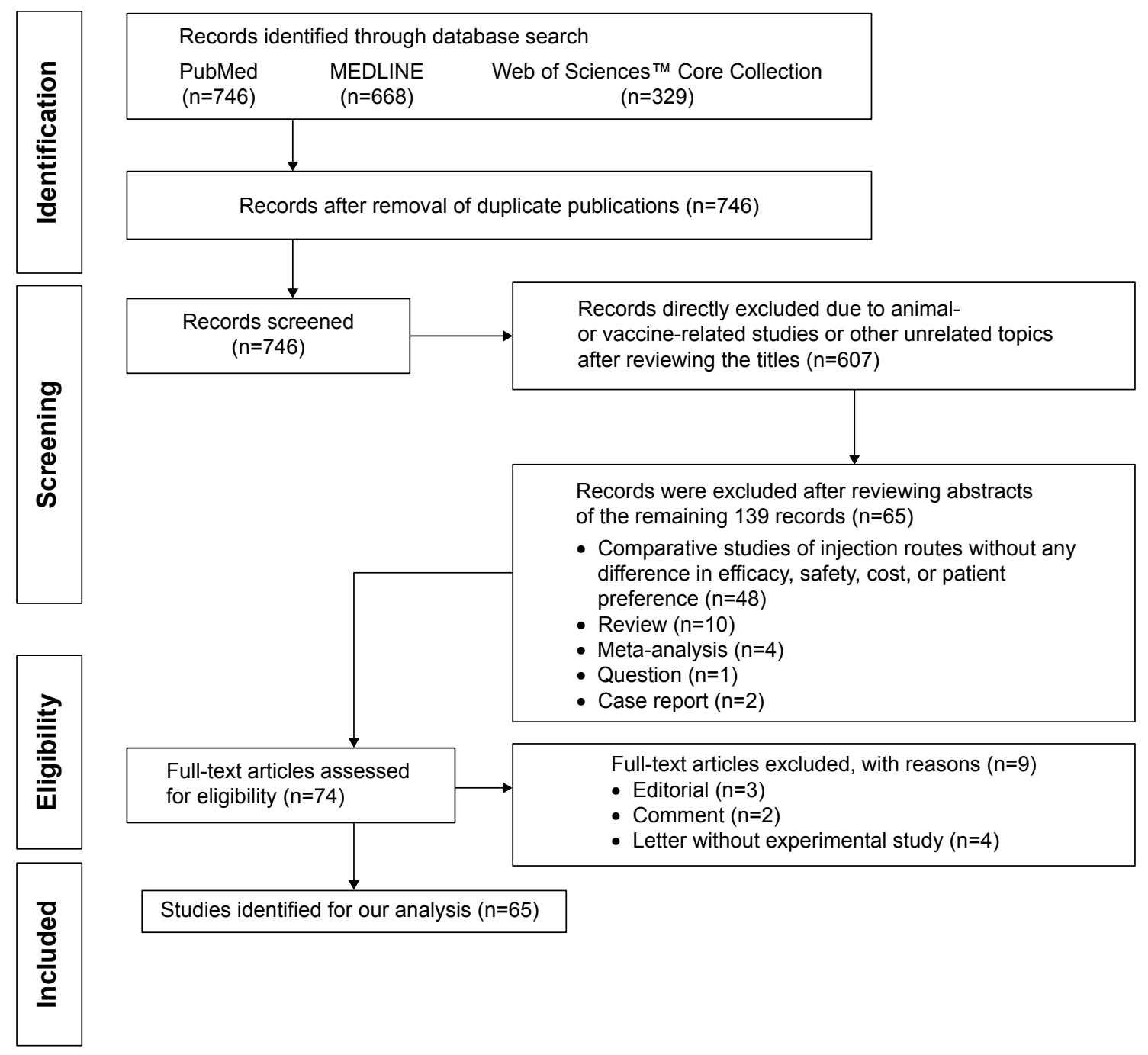

Figure I The flowchart of literature selection.

expanded literature retrieval with the search string - title/ abstract contains "(intramuscular and intravenous)" or "(intramuscular and subcutaneous)" or "(subcutaneous and intravenous)". An additional 20 original articles were identified for data mining. Prescribing information for related medications was also read by reviewer (QZ).

\section{Results}

\section{SC versus IV}

\section{Trastuzumab}

Trastuzumab is a key agent for human epidermal growth factor receptor 2 (HER2)-positive breast cancer in both the early and metastatic settings. It is given by IV infusion, with between 17 and 52 infusions in standard regimens over 1 year, as described in prescribing information for Herceptin $^{\circledR}$ (trastuzumab; Genentech, Inc., South San Francisco, CA, USA). ${ }^{8}$ However, IV administration of trastuzumab requires substantial time commitments on patients and health care staff, and may cause patient discomfort. In 2013, the European Union approved a new SC formulation of trastuzumab for use in patients with early or metastatic breast cancer. The SC formulation is administered in 2-5 minutes rather than 30-90 minutes with the standard IV form, and it contains a recombinant human hyaluronidase ( $\mathrm{rHuPH} 20$ ) that opens up channels in the extracellular matrix of the skin and enables trastuzumab to be administered via the SC route. ${ }^{9}$ In the international, randomized, two-cohort PrefHer study, patients with HER2-positive early breast cancer were randomized to receive four adjuvant cycles of $600 \mathrm{mg}$ fixeddose SC trastuzumab followed by four cycles of standard IV trastuzumab, or vice versa. Compared with IV trastuzumab, SC trastuzumab has shown non-inferior efficacy, similar pharmacokinetic and safety profile, and higher patient preference $(88.9 \%$ versus $9.6 \%, P<0.0001){ }^{10,11}$ Results from the 
Phase III HannaH study also confirmed comparable efficacy and safety profile of trastuzumab for HER2-positive early breast cancer between the IV and SC groups. ${ }^{12}$

\section{Rituximab}

Rituximab is a part of standard therapy for many nonHodgkin's lymphoma patients. Prescribing information for Rituxan ${ }^{\circledR}$ (rituximab; Genentech, Inc.) notes that it is given by IV infusion. ${ }^{13}$ The fixed dose of $1,400 \mathrm{mg}$ SC rituximab was confirmed to have non-inferior serum trough concentrations relative to IV rituximab $375 \mathrm{mg} / \mathrm{m}^{2}$ dosing during maintenance, with a comparable safety profile. ${ }^{14}$ Rule et al conducted a time and motion study to investigate the staff time and costs associated with administration of SC and IV rituximab. ${ }^{15}$ Compared with IV rituximab, SC rituximab per session was associated with reductions in active health care professional time (48.5 minutes versus 223.3 minutes), total mean staff costs, and patient time in the treatment room (70.0 minutes versus 263.8 minutes). Switching from IV to SC rituximab could increase treatment room capacity and patient throughput, as well as improving the patient experience. $^{15}$

Interestingly, the effect of dose on absorption of SC rituximab was observed in rats. Rituximab exhibited linear kinetics following IV administration; however, bioavailability following SC injection was inversely related to the dose level. The bioavailability values following $1 \mathrm{mg} / \mathrm{kg}, 10 \mathrm{mg} / \mathrm{kg}$, and $40 \mathrm{mg} / \mathrm{kg}$ injected at the back were approximately $70 \%$, $31 \%$, and $18 \%$, respectively. Saturable binding may be a major determinant of the nonlinear absorptive transport of rituximab. ${ }^{16}$

\section{Antitumor necrosis factor medications}

Antitumor necrosis factor (anti-TNF) medications are indicated for the treatment of chronic inflammatory conditions such as rheumatoid arthritis, inflammatory bowel disease, and psoriasis. Anti-TNF medications include monoclonal antibodies (eg, infliximab, adalimumab, certolizumab pegol, and golimumab) and circulating receptor fusion protein such as etanercept. A Phase I, open-label trial evaluated the effects of SC or IV golimumab on inflammation markers (eg, C-reaction protein, interleukin-6, serum amyloid A, TNF receptor II, matrix metalloproteinase-3, haptoglobin, ferritin, and hepcidin) in patients with rheumatoid arthritis. Patients were randomized to receive SC golimumab $100 \mathrm{mg}$ at baseline and every 4 weeks thereafter through week 20 or IV infusions of golimumab $2 \mathrm{mg} / \mathrm{kg}$ at baseline and week 12 . Decreases in concentrations of these inflammatory markers were maintained through week 24 in SC group but began to reverse after week 8 in IV group, indicating that SC route was superior to IV route in golimumab treatment of rheumatoid arthritis. ${ }^{17}$

Sylwestrzak et al examined patient preferences regarding available anti-TNF agents and mode of administration options. ${ }^{18}$ Participants were asked about their use of anti-TNF agents, locations of administration, preferences for IV or SC route, interest in anti-TNF home therapy options, and their physician's role in their decision-making process. The SC group showed a higher preference for the injection route they were using compared with the IV group; that is, $89.9 \%$ of the SC group preferred the SC route, whereas $71.8 \%$ of the IV group preferred the IV route $(P<0.001)$. Another questionnaire survey identified the determinants of patient preferences in the choice of anti-TNF therapies for rheumatoid arthritis. ${ }^{19}$ The IV and SC routes of administration were preferred by $50.2 \%$ and $49.8 \%$, respectively. Reasons for the choice of IV route were the safety of treatment at the hospital and the reassuring effect of physician presence. The SC route was chosen for the convenience of treatment and in particular for home treatment. Patients who were dissatisfied with current therapy due to side effects preferred SC administration ( $P=0.029)$, whereas patients choosing the IV route had higher scores on "today pain" $(P=0.047)$ and "articular pain" $(P=0.023)$ of the Rheumatoid Arthritis Disease Activity Index. The questionnaire survey indicates that physician should discuss with patients about the choice of injection route because individual preference seems to be determined by personal attitudes toward safety and convenience, by past experience, and by the perception of current disease status.

\section{Bortezomib}

Bortezomib is indicated for treating relapsed multiple myeloma and mantle cell lymphoma. The two most significant bortezomib-related issues include peripheral neuropathy and the IV route required for its administration. In January 23, 2012, the US Food and Drug Administration (FDA) approved a supplemental new drug application for Velcade ${ }^{\circledR}$ (bortezomib; Takeda Pharmaceutical Company Limited, Osaka, Japan) which had updated the label to include the SC method of administration in all approved indications. The approval was based on results from a randomized, Phase III, open-label, international, non-inferiority trial which compared the efficacy and safety of SC versus IV bortezomib twice weekly in patients with relapsed multiple myeloma. SC bortezomib exhibited non-inferior efficacy to IV bortezomib and was associated with a lower incidence of neuropathy 
(eg, peripheral neuropathy of any grade [38\% versus 53\%, $P<0.05$ ], grade 2 or worse [24\% versus $41 \%, P<0.05$ ], and grade 3 or worse $[6 \%$ versus $16 \%, P<0.05]) .{ }^{20}$ Moreau et al revealed that $\mathrm{SC}$ administration resulted in equivalent bortezomib plasma exposure to IV administration and comparable blood $20 \mathrm{~S}$ proteasome inhibition. ${ }^{21}$ An updated survival analysis of a randomized Phase III study showed that SC bortezomib was associated with comparable efficacy regarding time to progression, progression-free survival and overall survival, and significantly lower rates of peripheral neuropathy compared with IV bortezomib. ${ }^{22}$

Barbee et al quantified the difference in efficiency practice variables and preferences regarding SC versus IV bortezomib route in patients with multiple myeloma who received at least one dose each of SC and IV administration. Compared to IV bortezomib, SC bortezomib was more time efficient for the patient and institution (eg, a 38\% reduction in chair time $[P<0.001]$ and a $27 \%$ reduction in infusion center visit time $[P<0.001])$ and was preferred by $68 \%$ of patients $(P=0.0002) .{ }^{23}$ Interestingly, prescribing information for Velcade ${ }^{\circledR}$ does not specify the anatomical site of SC injection, whereas evidence has shown that SC injections of bortezomib in the abdomen cause fewer grade 2 injection site reactions than those in the thigh $(1.6 \%$ versus $11.0 \%, P<0.001) .{ }^{24}$

In the Phase III MMY-3021 study, ${ }^{25}$ response rates were $52 \%$ and $57 \%$ with SC and IV bortezomib, respectively, in patients with creatinine clearance $(\mathrm{CrCl})>50 \mathrm{~mL} / \mathrm{min}$, and $53 \%$ and $31 \%$ in patients with $\mathrm{CrCl}$ of $20-50 \mathrm{~mL} / \mathrm{min}$. Clinical benefit of bortezomib in terms of renal impairment reversal (to $\mathrm{CrCl}>60 \mathrm{~mL} / \mathrm{min}$ ) was reported in $30 \%$ of patients receiving $\mathrm{SC}$ bortezomib and $15 \%$ of patients receiving IV bortezomib. Long-term outcomes were similar with $\mathrm{SC}$ and IV bortezomib in patients with $\mathrm{CrCl}>50 \mathrm{~mL} / \mathrm{min}$ (median time to progression 9.7 months and 9.8 months) and with SC bortezomib in patients with $\mathrm{CrCl}$ of $20-50 \mathrm{~mL} / \mathrm{min}$ (10.5 months). It indicates that SC bortezomib is more suitable than IV bortezomib for patients with renal dysfunction.

\section{Amifostine}

Amifostine is a cytoprotective agent. Prescribing information for Ethyol ${ }^{\circledR}$ (amifostine; MedImmune Pharma B.V., 6545 CG Nijmegen, The Netherlands) notes IV infusion as the administration method. The IV administration of amifostine is associated with reversible clinical hypotension, protracted emesis, and malaise in various percentages of patients. ${ }^{26}$ Bardet et al compared the compliance with and efficacy of IV and SC amifostine in patients undergoing radiotherapy for head and neck cancer. Patients were randomly assigned to receive either IV amifostine $\left(200 \mathrm{mg} / \mathrm{m}^{2}\right.$ daily for 3 minutes, 15-30 minutes before irradiation) or SC amifostine (500 mg, two sites, 20-60 minutes before irradiation). SC amifostine was not significantly superior to IV amifostine regarding patient compliance or efficacy; however, it was associated with significantly lower acute toxicity including grade $1-2$ hypotension ( $8 \%$ for SC versus $19 \%$ for $\mathrm{IV}, P=0.01)$, grade $1-2$ skin rash $(21 \%$ for $\mathrm{SC}$ versus $9 \%$ for IV,$P=0.01$ ), and local pain ( $8 \%$ for SC versus $0 \%$ for IV , $P=0.003) .{ }^{27}$ Koukourakis et al prospectively evaluated the tolerance difference between SC and IV route in patients receiving chemotherapy. Protracted vomiting or clinical hypotension was absent in SC group, and the tolerance profile in SC group was significantly better than the IV group $(P=0.001) .{ }^{28}$ The absence of hypotension with SC administration facilitates patient monitoring and management in tumor treatment departments. Meanwhile, switching to the $\mathrm{SC}$ route in patients with poor tolerance to IV route allows the continuation of cytoprotection with minor side effects. ${ }^{29}$

\section{Recombinant human granulocyte-macrophage colony-stimulating factor}

Recombinant human granulocyte-macrophage colonystimulating factor (rhGM-CSF) can stimulate the production of white blood cells and thus prevent neutropenia following chemotherapy. It can be administered via IV or SC route. Rosenfeld et al compared the toxicity and hemopoietic effects of SC and IV rhGM-CSF in patients with primary myelodysplasia. Increases in the absolute neutrophil count exhibited a dose-response relationship and were more pronounced with $\mathrm{SC}$ than IV administration. Compared to a 2-hour infusion of rhGM-CSF, SC administration is more myelostimulatory without an increase in toxicity. ${ }^{30}$ Lieschke et al demonstrated that bacterially synthesized rhGM-CSF was an ineffective stimulant of leukopoiesis when given as a bolus $(0.3-3 \mu \mathrm{g} /$ $\mathrm{kg}$ /day), but it was effective when administered by 2-hour IV infusion (3-20 $\mu \mathrm{g} / \mathrm{kg} /$ day). Moreover, IV dose of rhGM-CSF was less potent at inducing a leukocytosis than equivalent SC doses and was associated with a higher incidence of generalized rash $(P<0.01)$ and first-dose reactions $(P<0.05){ }^{31}$

\section{Granulocyte colony-stimulating factor}

Granulocyte colony-stimulating factor (G-CSF) can stimulate the bone marrow to produce granulocytes and stem cells. It is administered to oncology patients via SC or IV routes. Paul et al conducted a randomized, open-label trial to compare IV versus SC G-CSF administration to hospitalized hemato-oncological patients receiving chemotherapy. ${ }^{32}$ The mean time 
to neutropenia resolution was longer with IV G-CSF compared with SC G-CSF (7.9 days versus 5.4 days, $P=0.001$ ), indicating that bolus IV G-CSF could result in longer neutropenia duration than SC administration. ${ }^{32}$ Eguchi et al evaluated the efficacy and toxicity of recombinant human G-CSF given subcutaneously in patients with advanced lung cancer undergoing intensive chemotherapy. When G-CSF is given subcutaneously, the dose required for a comparable effect in alleviating neutropenia is $50 \%$ of that required when it is given intravenously. ${ }^{33}$

\section{Recombinant interleukin-2}

Recombinant human interleukin-2 (rIL-2) has demonstrated survival benefits over chemotherapy for the majority of patients with metastatic renal cell carcinoma (mRCC). The rIL-2 can be administered as high-dose IV bolus injection, continuous IV infusion, or SC administration in a lower dosage regimen. Hospitalization/intensive care is required throughout due to the side effects if rIL-2 is intravenously delivered. ${ }^{34}$ Geertsen et al compared the safety and efficacy of administration by SC and continuous IV infusion of rIL-2 in patients with $\mathrm{mRCC}$. Compared with continuous IV infusion, SC delivery of rIL-2 was associated with improved tolerability. SC administration was associated with more patients experiencing stable disease (50.5\% versus $29.8 \%$ ), fewer patients undergoing disease progression $(35.0 \%$ versus $43.6 \%)$, lower incidence of severe adverse events $(46 \%$ versus $76 \%, P<0.001$ ), and fewer patients requiring dose reductions due to toxicity ( $20 \%$ versus $82 \%$ ). There was no difference between two injection routes of rIL-2 regarding efficacy in terms of overall survival, duration of response, and response rate. ${ }^{35} \mathrm{~A}$ prospective, non-randomized study showed that low-dose SC interleukin-2 therapy was associated with low clinical and hematologic toxicity after autologous transplantation, while the immunomodulation achieved was no less than that achieved with the IV route. ${ }^{36}$

\section{Immunoglobulin}

A shift from IV immunoglobulin (IV-IG) to less laborintensive SC immunoglobulin (SC-IG) has the potential to help alleviate nurse shortages and reduce overall health care costs. ${ }^{37}$ Martin et al demonstrated that rapid push home-based SC-IG was less costly than hospital-based IV-IG for immunoglobulin replacement therapy in adult primary immunodeficiency patients in the Canadian context. ${ }^{38}$ A systematic review revealed that changing IG replacement therapy from IV-IG to SC-IG may be of benefit to qualified patients with primary immunodeficiency. ${ }^{39}$ Ducruet et al revealed the pharmacoeconomic advantages of SC-IG versus IV-IG treatment in a Canadian pediatric center. The $\mathrm{SC}$ route was less costly than the IV route from either the patient perspective $(P<0.001)$ or the government perspective $(P<0.001){ }^{40}$ Kittner et al evaluated the attitude of patients toward switching to SC-IG home therapy from IV-IG therapy by a questionnaire survey. Patients on SC therapy were significantly younger than those in the IV treatment group $(37 \pm 9.1$ years versus 51.2 \pm 14.5 years, $P<0.001)$. Compared with the SCtreated group, more IV-treated patients were afraid of being more busy with self-administration $(P<0.001)$, being worried about severe adverse reactions at home $(P<0.001)$, and had higher points on a Likert scale about the statement "I dislike to puncture myself' $(P<0.001){ }^{41}$

Another study investigated the perceptions of the SC method and the perceptions of the home therapy regime among patients who already had considerable experience of this therapy. Significant correlations were found between age and perception of the lifelong treatment with SC infusion of IG for primary antibody deficiencies. The younger patients perceived the SC infusions more uncomfortable and were less determined to continue with the therapy as compared with the older patients $(P<0.01)$. Additionally, the women were more positive concerning the SC method $(P<0.05)$, as compared with the men. ${ }^{42}$

The primary disadvantage of SC-IG is the inherent resistance of the extracellular matrix, which limits the volume infusible in one site (usually $15-30 \mathrm{~mL}$ ), and requires multiple infusion sites weekly or every second week, rather than a single monthly IV infusion. Wasserman et al investigated the efficacy and tolerability of rHuPH20-facilitated SC-IG in patients with primary immunodeficiency. Eighty-seven patients with primary immunodeficiency aged $\geq 2$ years received 10\% IV-IG for 3 months, and then rHuPH20facilitated SC-IG $(n=83)$ for approximately 14-18 months at $108 \%$ of the IV-IG dose. rHuPH20-facilitated SC-IG brings together the advantages of IV-IG and SC-IG, that is, combining the once-monthly, single-site infusion of IV-IG with the option of home-based self-administration of SC-IG. The rHuPH20-facilitated SC-IG had a 20\% higher bioavailability than SC-IG and caused fewer systemic reactions than IV infusion ( $8.3 \%$ versus $25.0 \%$ ), while it was effective, safe, and pharmacokinetically equivalent to IV-IG. ${ }^{43}$

\section{Insulin}

Bodur et al compared continuous SC insulin infusion via an insulin pump with the traditional continuous IV infusion method for tight glycemic control among patients in medical intensive care unit. Although there was no significant difference in mortality and hypoglycemic events between 
the groups, the SC insulin group achieved better glycemic control and significantly lowered daily insulin bolus and infusion requirements. ${ }^{44}$

On the contrary, IV insulin has advantages over SC insulin in some clinical circumstances. Neff et al studied the efficacy of protocol-based IV insulin delivery as compared to $\mathrm{SC}$ insulin prescribed individually outside of the critical care setting. Among a total of 122 who developed parenteral nutrition (PN)-associated hyperglycemia, those receiving IV insulin achieved glycemic target for more time than those on the SC regimen ( $62 \%$ versus $43 \%, P=0.008)$, indicating that IV insulin should therefore be considered optimum therapy for patients with $\mathrm{PN}$-associated hyperglycemia in the noncritically ill inpatient setting. ${ }^{45}$ Use of perioperative continuous IV insulin infusion in diabetic patients undergoing open-heart surgical procedures could significantly reduce major infectious morbidity and its associated socioeconomic costs. Compared with sliding-scale-guided intermittent SC insulin injections, continuous IV insulin infusion induced a significant reduction in perioperative blood glucose levels and significantly reduced the incidence of deep sternal wound infection $(0.8 \%$ versus $2.0 \%, P=0.01){ }^{46}$

Pezzarossa et al observed that the outcome difference between SC and IV route depended on the time of insulin administration for the perioperative management of diabetic patients. During the intraoperative period, the total insulin requirement expressed as the insulin-to-glucose ratio was significantly lower in subjects receiving IV insulin $(0.18 \pm 0.3$ versus $0.27 \pm 0.3$ in the SC group, $P<0.05$ ), whereas no difference was observed during the pre- and postoperative periods. It indicated that IV insulin administration achieved better glycemic control during the intraoperative period, whereas it did not offer advantages over the SC route during the other two periods. ${ }^{47}$

\section{Epoetin alfa}

Epoetin alfa may be given either as an IV or as an SC injection. Clinical and pharmacokinetic studies have shown that target hemoglobin or hematocrit levels can be maintained using a reduced epoetin dosage by switching from IV to SC administration. Wazny et al conducted a cost analysis of a conversion from IV to SC epoetin in patients receiving chronic in-center hemodialysis during a 6-month period of IV or SC usage. SC epoetin was associated with a yearly cost savings of US\$1135 per patient. ${ }^{48} \mathrm{~A}$ meta-analysis by Besarab et al concluded that the cost of epoetin was reduced substantially when administered via route of SC in comparison to IV. ${ }^{49} \mathrm{SC}$ epoetin is twice as efficient as IV epoetin for the treatment of anemia in hemodialysis patients, with a dose saving of 53\% $(P<0.001) .{ }^{50}$ Conversion of epoetin from SC to IV dosing could increase the epoetin dosage requirements by $26 \%-32 \%$ and costs of anemia therapy. Overall, epoetin doses increased. ${ }^{50-54}$

\section{Heparin}

Patient preference for IV or SC heparin in the treatment of deep venous thrombosis (DVT) was assessed in a randomized cross-over study. Twenty patients with venographically proven DVT were randomized to receive SC or IV heparin for 3 days followed by 3 days of the other treatment. Compared with IV administration, SC treatment was associated with significantly less discomfort at the injection site $(P<0.001)$, better mobility $(P<0.005)$, and patients' overall preference $(P<0.001) .{ }^{55}$ Assuming that the SC and IV routes were equally effective on the basis of the medical literature, Barber and Hoffmeyer compared the cost-effectiveness of SC heparin (20,000 IU, twice daily, prefilled syringes), a continuous IV infusion of 24,000 IU heparin in 24 hours, and the IV infusion of 48,000 IU heparin as two consecutive 12-hour infusions of 24,000 IU. Incorporating the cost of human resource in vein cannulation, infusion preparation, and medication administration with the use of heparin syringes, SC heparin therapy was significantly more cost-effective than IV heparin therapy. The reduction in cost and liberation of nursing time mean that the SC route should be preferred. ${ }^{56}$

\section{Ketamine}

Ketamine can suppress hyperalgesia and allodynia. Evidence has shown that IV ketamine is more appropriate than SC ketamine in controlling postoperative analgesia. Honarmand et al evaluated the clinical efficacy of preincisional IV or SC infiltration of ketamine $(0.5 \mathrm{mg} / \mathrm{kg})$ for postoperative pain relief after appendectomy. Visual analog scale scores were not significantly different between IV group and SC group at the time of arrival in the recovery room, and at 10 minutes, 20 minutes, and 30 minutes thereafter, but were significantly lower at 12 hours, 18 hours, and 24 hours after surgery in IV group compared with SC group $(P<0.05)$. Preincisional IV administration of low-dose ketamine provides analgesia for 24 hours after surgery without significant side effects in patients undergoing appendectomy, whereas SC ketamine at the same dose only controls analgesia within the first 6 hours after surgery. ${ }^{57}$

Ketamine is also known to have major cardiovascular side effects. It has been shown that, in some patients, ketamine may temporarily increase heart rate and blood pressure by increasing sympathetic nervous system activity. A prospective randomized double-blind study compared the efficacy 
of SC and IV ketamine $(0.6 \mathrm{mg} / \mathrm{kg})$ added to narcotics in patients scheduled for laparoscopic peritoneal dialysis catheter implantation. Results showed that SC ketamine was as effective as, but safer than, IV ketamine. There were no differences between two groups regarding pain intensity, recall rate during the surgery, and surgeon satisfaction; however, $\mathrm{SC}$ administration of ketamine for induction of conscious sedation is accompanied by a significantly lower rise in systolic blood pressure and rate-pressure product before skin infiltration, after insertion of the second trocar, and at the end of surgery. ${ }^{58}$

\section{Vitamin $\mathrm{KI}$}

The risk of bleeding complications associated with warfarin therapy increases when values of the international normalized ratio (INR) are $>5.0$. Raj et al observed the time course of reversal of anticoagulant effect of warfarin by vitamin K1 via IV or SC route. ${ }^{59}$ Twenty-two patients with asymptomatic prolongation of prothrombin time were prospectively randomized and treated with $1 \mathrm{mg}$ IV vitamin $\mathrm{K} 1$ or $1 \mathrm{mg}$ $\mathrm{SC}$ vitamin K1. Mean INR at baseline was 8.0 and 8.5 in the IV and SC groups, respectively. At 8 hours, mean INR was 4.6 in the IV group and 8.0 in the SC group $(P=0.006)$, and mean INR was 3.1 in the IV group and 5.0 in the SC group at 24 hours $(P=0.009)$. Mean decrease in INR 8 hours after administration of vitamin $\mathrm{K} 1$ was 3.4 in the IV group and 0.4 in the SC group $(P=0.02)$. Compared with the SC route of administration, IV vitamin $\mathrm{K} 1$ caused a more prompt reduction in the INR. The proportion of subjects with INR values $<5$ at 24 hours was $45 \%$ for the SC group and $95 \%$ for the IV group $(P<0.001) .{ }^{60}$ For patients excessively anticoagulated with warfarin, small doses of SC vitamin K1 may not correct the INR as rapidly or as effectively as IV administration, and higher doses must be considered for more rapid and complete reversal of anticoagulation by the $\mathrm{SC}$ route.

\section{Ceftriaxone}

SC ceftriaxone administration is approved for use in France, although IV and IM administration are currently FDA approved. Gauthier et al compared the IV administration of ceftriaxone to SC administration in patients older than 75 years. SC route seems to be preferred for fragile elderly patients, while it is not associated to an impaired effectiveness or to an increased death rate. Compared with the IV group, patients in the SC group were significantly older, more often bedridden, and more frequently had dementia. ${ }^{61}$ The reasons for using SC administration in weaker patients include a difficult venous access, risks related to venous access, and difficulty to maintain the venous access, especially in patients presenting with cognitive or behavioral disorders. Nevertheless, this does not justify an excessive use of SC administration, as for septic shock. Harb et al compared pharmacokinetics and safety of rHuPH20-facilitated SC ceftriaxone administration versus $\mathrm{SC}$ ceftriaxone preceded by SC saline placebo or IV ceftriaxone administration. ${ }^{62}$ IV ceftriaxone exhibited higher $C_{\max }$ and shorter $T_{\max }$ values than either SC treatment, while ceftriaxone area under the curve (AUC) did not differ significantly between the three administration routes. Compared with $\mathrm{SC}$ preceded by placebo, rHuPH20-facilitated SC achieved higher $C_{\max }$ and shorter $T_{\max }$.

\section{Opioids}

Daoust et al assessed the impact of age, sex, and route of administration on the incidence of adverse events due to opioid administration in the emergency department. The IV route was linked with higher rates of all adverse events, the $\mathrm{SC}$ route with moderate rates, and the oral route with fewer overall rates. Adjusted odds ratio (OR) (95\% confidence interval) of nausea/vomiting in IV and SC group relative to the oral group was 4.21 (3.12-5.67) and 2.44 (1.81-3.30), respectively. Regarding major adverse events, adjusted OR (95\% confidence interval) in IV and SC group relative to the oral group was $6.10(4.43-8.39)$ and 2.07 (1.48-2.89), respectively. ${ }^{63}$ Flexibility in the route of administration may contribute to better clinical outcomes. A prospective survey evaluated parenteral morphine-prescribing patterns among inpatients with pain from advanced cancer. There were five major inpatient prescribing patterns, that is, IV to oral, IV to SC, IV only, SC only, and mixed. The IV-to-oral group had more stable pain control than the IV-to-SC group. Pain control was $100 \%$ in the mixed group, compared with $67 \%$ in IV-only group, 33\% in SC-only group, $82 \%$ in IV-to-oral group, and $56 \%-75 \%$ in IV-to-SC group. ${ }^{64} \mathrm{Clinicians}$ should be knowledgeable about the appropriate and flexible use of different routes of administration for morphine and other opioids.

\section{IM versus IV}

\section{Epinephrine}

Epinephrine has a pivotal role as first-line treatment for acute anaphylaxis. Campbell et al compared rates of cardiovascular adverse events and epinephrine overdoses between various routes of epinephrine administration among patients with anaphylaxis in the emergency department. Occurrence rate 
of adverse cardiovascular events associated with IV bolus epinephrine was $10 \%$ compared with IM epinephrine (1.3\%) (OR 8.7, $P=0.006$ ). Similarly, overdose occurred with IV bolus epinephrine compared with IM epinephrine $(13.3 \%$ versus $0 \%$; OR 61.3, $P<0.001) .{ }^{65}$ Therefore, there is a need for extreme caution and further education about IV bolus epinephrine in anaphylaxis.

\section{Hepatitis B immunoglobulin}

Hepatitis B virus (HBV)-infected patients may receive longterm combination therapy with hepatitis B immunoglobulin (HBIG) and oral antiviral medication to prevent reinfection after orthotopic liver transplantation (OLT). Costs of IV HBIG are extremely higher than those of IM HBIG. Faust et al studied the outcome of patients after a switch from 2,000 IU IV HBIG (Hepatect ${ }^{\circledR}$, Biotest AG, Dreieich, Germany) administered every 2 weeks to 2,000 IU IM HBIG (Behring ${ }^{\circledR}$, Aventis-Behring, Marburg, Germany) given once a month and after the patients initially treated with IM HBIG were discharged from the hospital. Long-term administration of IM HBIG could save up to $60 \%$ of the usual costs for IV prophylaxis of HBV reinfection in patients after OLT. In combination with lamivudine, long-term IM HBIG therapy is as efficient as IV HBIG treatment, but its lower costs clearly favor its use in preventing HBV reinfection after OLT. ${ }^{66}$ Economic analysis showed an average cost-effectiveness ratio of combination IM HBIG plus lamivudine of US\$52,600 per recurrence prevented, which was far below the cost of lamivudine monotherapy and of IV HBIG alone or in combination with lamivudine. ${ }^{67} \mathrm{IM} \mathrm{HBIG}$ in combination with lamivudine offers a safe, effective, and cost-effective approach to preventing HBV recurrence after OLT.

A questionnaire evaluated the impact of HBIG prophylaxis on the quality of life of liver transplant recipients, and the results showed that the route of HBIG administration could have a significant impact on specific health-related quality-of-life (HRQOL) domains beyond a patient's satisfaction. In comparison with patients on IV HBIG, patients on IM HBIG reported significantly better HRQOL scores on the flexibility ( $P=0.01)$ and negative feelings scales $(P=0.04)$, but they reported worse HRQOL scores on the side effects scale $(P<0.001)$. There was no difference between the two routes of HBIG administration regarding satisfaction, positive feelings, impact, and support scales. ${ }^{68}$

\section{Pegaspargase}

Pegaspargase, a modified version of L-asparaginase that is covalently conjugated to monomethoxypolyethylene glycol, is important for treatment of acute lymphoblastic leukemia. The recommended dose of Oncaspar ${ }^{\circledR}$ (Pegaspargase, Sigma-Tau Pharmaceuticals, Inc., Gaithersburg, $\mathrm{MD}, \mathrm{USA}$ ) is $2,500 \mathrm{IU} / \mathrm{m}^{2}$ intramuscularly or intravenously. Anaphylaxis and serious allergic reactions can occur in patients receiving Oncaspar ${ }^{\circledR}{ }^{69}$ There is a potential concern that the IV route may result in more severe allergic reactions due to immediate exposure to reactive antibodies in the blood, which is delayed after IM administration. Occurrence rate of allergic reactions was $9 \%$ in newly diagnosed patients receiving IM pegaspargase, significantly less than that $(36 \%)$ in patients receiving IV pegaspargase $(P=0.019)$, whereas the severity of reaction was not increased with IV versus IM..$^{70}$ A study by Petersen et al showed an increased incidence of allergy in children with acute lymphoblastic leukemia who received IV pegaspargase compared to IM (19.5\% versus $10.7 \%, P=0.028)$ and a more rapid onset of allergic reactions to IV pegaspargase (ie, time to onset of symptoms was within 30 minutes for $96.3 \%$ of evaluable IV patients versus $18.2 \%$ of evaluable IM patients, $P<0.001)^{71}$

\section{Antibiotics}

Generally, antibiotics available for IM injection should be considered as an economically efficient alternative to IV injections in appropriate patients. Milkovich and Piazza assessed the economic efficiencies of IM and IV administration of antibiotics. Regarding cefazolin, gentamicin, penicillin, and imipenem, the IM route was found to be up to one-tenth the expense of the IV route and may facilitate early discharge and self-administration in the home. ${ }^{72}$ The recommended dosage of imipenem-cilastatin is $250 \mathrm{mg}$ to $1 \mathrm{~g}$ given intravenously every 6-8 hours, or IM doses of no more than $1.5 \mathrm{~g}$ daily, usually for 5-14 days. A study showed that the dosing of imipenem-cilastatin $750 \mathrm{mg}$ given intramuscularly every 12 hours is a more cost-effective method of drug delivery with equal efficacy and safety when compared to imipenem-cilastatin $500 \mathrm{mg}$ given intravenously every 6 hours. Incorporating acquisition costs, salaries of pharmacists and technicians for manufacturing infusion, and nursing administration costs, the mean total drug therapy costs were significantly greater for the IV group as compared to the IM group $(P<0.01) .{ }^{73}$ Pharmacokinetic studies of isepamicin, teicoplanin, and ceftriaxone following administration by IV infusion or IM injections showed complete absorption following IM administration and the feasibility of interchangeable administration by either route without compromising clinical efficacy. ${ }^{74-76}$ 


\section{Ketamine}

Ketamine can be given by IV and SC route. Momeni et al compared the effect of IV ketamine $(1 \mathrm{mg} / \mathrm{kg})$ and IM ketamine $(4 \mathrm{mg} / \mathrm{kg})$ in children admitted to the emergency department. There was no significant difference in complications and level of sedation in 5 minutes, 10 minutes, and 15 minutes in both groups, but sedation was longer in the IM group $(P<0.05)$. Thus, IV ketamine may be the desirable approach for orthopedic procedures in sedating children. ${ }^{77}$ Ramaswamy et al compared the side-effect profiles of IM or IV ketamine and investigated which injection route will lead to quicker discharge from the emergency department. Total time in the emergency department (triage to discharge) between the two routes was not significantly different. However, time from drug administration to patient discharge was 21 minutes shorter for IV compared with IM administration $(P<0.001)$. Moreover, IM group was more prone to adverse events compared with IV group $(P=0.01) .{ }^{78}$ Roback et al compared adverse events, efficacy, and length of sedation of $1 \mathrm{mg} / \mathrm{kg}$ IV versus $4 \mathrm{mg} / \mathrm{kg}$ IM ketamine procedural sedation and analgesia for orthopedic procedures in the emergency department. Patients in the IM group reported significantly less pain and lower distress during the painful procedure but experienced more commonly vomiting and significantly longer length of sedation. ${ }^{79}$

\section{Morphine}

IV morphine has a more rapid and extensive initial effect compared with IM, which is supported by the findings of the pharmacokinetic study by Dale et al. ${ }^{80}$ Dale compared the time course of morphine and metabolite concentrations in serum and cerebrospinal fluid (CSF) after IV and IM administration of morphine $10 \mathrm{mg}$ after surgery. The uptake of morphine to the CSF was consistently higher after IV administration than after IM administration. The higher CSF concentration may be caused by an initially higher morphine blood/CSF gradient following IV morphine injection. Tveita et al compared patient safety and analgesic efficacy of a single high dose of morphine given intramuscularly or intravenously for postoperative pain management. ${ }^{81}$ The IV group experienced a significantly faster onset of analgesic effect than the IM group (5 minutes versus 20 minutes). During 5-25 minutes after morphine administration, pain status in the IV group was significantly improved compared with the IM group. A $10 \mathrm{mg}$ bolus dose of IV morphine given to patients with moderate pain after surgery can provide more rapid and better initial analgesia than $10 \mathrm{mg}$ dose of IM morphine without causing severe respiratory depression. A prospective study investigated the safety, efficacy, and complication rate of intermittent IM versus continuous IV infusion of morphine sulfate in 46 nonventilated children following major chest, abdominal, or orthopedic surgical procedures. Mean pain scores in the IV group were significantly lower than those of the IM group $(P<0.01)$. IV infusion provided better pain relief than IM injections without respiratory depression. ${ }^{82}$

\section{Antivenom}

Redback spider antivenom can be given by IM or IV route. The manufacturer recommends IM use, with IV administration reserved for life-threatening cases. Ellis et al compared the efficacy of IV versus IM antivenom in the treatment of redback spider envenoming and observed that the proportion pain-free at 24 hours in the IV group was better compared with the IM group (76\% versus $21 \%$ ), although redback spider antivenom was initially effective by both IM and IV routes..$^{83}$ Isbister et al compared antivenom serum concentrations following IV and IM administration of redback spider antivenom in ten patients. ${ }^{84}$ Antivenom could not be detected in patients receiving one or two doses of IM antivenom at any time point but could be detected in all patients receiving IV antivenom. Thus, IM redback spider antivenom should not be recommended in the treatment of redback spider bite.

\section{IM versus SC}

\section{Epinephrine}

A prospective, randomized, blinded, parallel-group study in 17 children with a history of anaphylaxis compared two injection methods ( $\mathrm{SC}$ injection of $0.01 \mathrm{~mL} / \mathrm{kg}$ epinephrine solution, maximum $0.3 \mathrm{~mL}$ [ $0.3 \mathrm{mg}$ ], or $0.3 \mathrm{mg}$ IM epinephrine from an autoinjector) ${ }^{85}$ In nine children who received SC epinephrine, the mean $C_{\text {max }}(1,802 \pm 214 \mathrm{pg} / \mathrm{mL})$ was achieved at a mean time of 34 minutes. However, in eight children who received IM epinephrine, $C_{\max }(2,136 \pm 351 \mathrm{pg} / \mathrm{mL})$ was achieved at a mean time of 8 minutes. The $T_{\max }$ exhibited statistically significant difference between two groups (34 \pm 14 minutes for SC versus $8 \pm 2$ minutes for IM, $P<0.05$ ). Only two out of the nine children receiving SC epinephrine achieved $C_{\max }$ by 5 minutes, while six out of the eight children receiving IM epinephrine achieved $C_{\max }$ by 5 minutes. Fatal anaphylaxis is associated with delayed epinephrine administration. Therefore, the IM route of injection is preferable during an episode of systemic anaphylaxis. A retrospective review in a military hospital showed that epinephrine was given largely by the SC route and no IM epinephrine was administered. Greater educational efforts and collaboration are needed between the allergy community and 
other providers regarding the importance of administering epinephrine intramuscularly. ${ }^{86}$

The advantage of IM administration over SC administration is challenged by the anatomical site of injection. Simons et al conducted a prospective, randomized, blinded, placebo-controlled, six-way cross-over study of IM versus $\mathrm{SC}$ injection of epinephrine $(0.3 \mathrm{mg})$ in young men. $C_{\max }$ values of IM epinephrine were significantly higher after injection into the thigh than after injection into the upper arm $(9,722 \pm 4,801 \mathrm{pg} / \mathrm{mL}$ versus $1,821 \pm 426 \mathrm{pg} / \mathrm{mL}, P<0.01)$. An identical dose of epinephrine injected IM into the deltoid did not result in significant elevation of $C_{\max }$ in comparison with endogenous epinephrine concentrations measured after saline solution injections.$^{87}$ The greater absorption of epinephrine from the vastus lateralis muscle in comparison with the deltoid muscle is most likely due to the greater blood flow in the vastus lateralis. Therefore, IM injection of epinephrine into the thigh was recommended as the preferred route and site of injection of epinephrine in the initial treatment of anaphylaxis; otherwise, the advantage of IM epinephrine versus SC epinephrine will disappear.

\section{Interferon-beta-la}

Interferon-beta-1a (IFN $\beta 1$ a) is indicated for the treatment of patients with relapsing forms of multiple sclerosis to slow the accumulation of physical disability and decrease the frequency of clinical exacerbations. REBIF ${ }^{\circledR}$ (IFN $\beta 1 \mathrm{a}$; Merck $\mathrm{KGaA}$, Darmstadt, Germany) is formulated as a sterile solution in a prefilled syringe or REBIF Rebidose autoinjector intended for SC injection, and its recommended dose is $22 \mu \mathrm{g}$ or $44 \mu \mathrm{g}$ three times weekly. ${ }^{88} \mathrm{AVONEX}^{\circledR}$ (IFN $\beta 1 \mathrm{a}$; Biogen Idec Inc., Berkshire, UK) is formulated as a lyophilized powder, single-use prefilled syringe, or single-use prefilled autoinjector intended for IM injection, and its recommended dose is $30 \mu \mathrm{g}$ once a week. ${ }^{89}$

The EVIDENCE trial concluded that administering high-dose/high-frequency SC IFN $\beta 1$ a was more effective in preventing relapses among patients with relapsing multiple sclerosis than low-dose weekly IM IFN $\beta 1$ a after 64 weeks. SC IFN $\beta 1$ a was estimated to prevent 0.50 relapses and save 23 relapse-free days per patient, resulting in greater health benefits over 4 years than IM IFN $\beta 1 \mathrm{a} .{ }^{90}$ Calabrese et al compared the effects of IM IFN $\beta 1$ a and SC IFN $\beta 1$ a on the development of cortical lesions and cortical atrophy in patients with relapsing-remitting multiple sclerosis. After 12 months, $74 \%$ of untreated patients developed greater than or equal to one new cortical lesion (mean 1.6) compared with $64 \%$ of IM group (mean 1.2, $P=0.021$ ) and $26 \%$ of SC group (mean $0.4, P<0.001$ ). After 24 months, greater than or equal to one new cortical lesion was observed in $82 \%$ of untreated (mean 3.0), $72 \%$ of IM IFN $\beta 1$ a-treated (mean 1.6, $P<0.001$ ), and $52 \%$ of SC IFN $\beta 1$ a-treated patients (mean $0.8, P<0.001$ ). The SC group exhibited faster and more pronounced effects in decreasing new cortical lesions development and cortical atrophy progression compared with IM group. ${ }^{91}$ However, a retrospective administrative claims analysis showed that the once-weekly IM IFN $\beta 1$ a cohort of patients with multiple sclerosis had significantly higher regression-adjusted odds of adherence compared with the three times weekly SC IFN $\beta 1$ a cohort, while there were no consistent differences in persistence between the two cohorts. The underlying mechanism for adherence difference may be possibly attributable to IM IFN $\beta 1$ a's less frequent dosing schedule. ${ }^{92}$

\section{Methotrexate}

For the treatment of rheumatic diseases, the antimetabolite drug methotrexate (MTX) can be administered weekly by different routes: oral, SC, or IM. Studies compared the serum concentrations and the pharmacokinetics of low-dose MTX after both IM and SC injections in patients with rheumatoid arthritis. Values of the $C_{\max }, T_{\max }$, and AUC for IM injections were not significantly different from these values for SC injections, indicating that IM and SC are interchangeable routes. SC administration may be a more convenient and less painful way of administering low-dose MTX. ${ }^{93,94}$ Arthur et al reported the findings of a 13-week study to compare the safety and efficacy of MTX administered by IM and SC injection. Although serum MTX levels were not significantly affected by the route of administration, seven out of eight preferred self-administration by the SC route at home. Self-administration was associated with reduced hospital visits and improved patient satisfaction; therefore, parenteral MTX should be prescribed by the SC route instead of the IM route. ${ }^{95}$

Interestingly, tolerability and patient/physician satisfaction with SC MTX were closely related with formulation characteristics. Müller-Ladner et al determined preference, satisfaction, usability, and local tolerability by patients, physicians, and study nurses of two subcutaneously administered MTX formulations of different concentrations. ${ }^{96}$ MTX treatment consisted of $20 \mathrm{mg} /$ week administered as a mediumconcentration formulation (MC) $(2.0 \mathrm{~mL}$ of $10 \mathrm{mg} / \mathrm{mL}$ solution in prefilled syringe; separate needle) or a highconcentration formulation (HC) $(0.4 \mathrm{~mL}$ of $50 \mathrm{mg} / \mathrm{mL}$ in prefilled syringe; pre-attached needle). At the end of the study, 93\% of the patients preferred $\mathrm{HC}$ over MC as further treatment. Overall assessment of HC was "good" or "very good" 
in $90.6 \%$ versus $34.4 \%$ of MC-treated patients. Physician's and patients' global assessment of syringe usability showed highly statistically significant differences $(P<0.0001)$ in favor of HC. The total smaller volume of administered drug and the improved usability of a pre-attached needle in combination with a smaller prefilled syringe resulted in preference of the patients of $\mathrm{HC}$ over MC.

\section{Human chorionic gonadotropin}

Human chorionic gonadotropin (hCG) is used to induce final oocyte maturation and to provide luteal phase support during in vitro fertilization treatment. $\mathrm{hCG}$ is usually given via IM route, but SC route has also been described. Stelling et al evaluated serum and follicular fluid levels of hCG after an IM or SC injection of 10,000 IU of hCG 36 hours after injection at the time of oocyte retrieval. SC administration achieves a significantly higher hCG level in serum (348.6 $\pm 98 \mathrm{IU} / \mathrm{L}$ versus $259.0 \pm 115 \mathrm{IU} / \mathrm{L}, P=0.014)$ and follicular fluid (233.5 $\pm 85 \mathrm{IU} / \mathrm{L}$ versus $143.4 \pm 134 \mathrm{IU} / \mathrm{L}$, $P=0.021$ ) compared with IM group despite of a nonsignificant difference in pregnancy rates between the two groups. SC hCG obtains the desired clinical effects with less patient inconvenience. ${ }^{97}$

Obese women had markedly lower $C_{\max }$, AUC, and average concentration $\left(C_{\mathrm{av}}\right)$ of $\mathrm{hCG}$ as compared with normal-weight women after SC injection (all $P<0.05$ ); however, the pharmacokinetic parameters were similar for normal-weight and obese women after IM injection. ${ }^{98}$ Thus, IM route may be more suitable for obese women who would receive $\mathrm{hCG}$.

\section{Hepatitis B immunoglobulin}

Despite current protocols allow for HBIG administration either intravenously or intramuscularly, experience with the SC administration of post-transplant HBIG has been reported. Singham et al examined the efficacy and patient preference of SC administration of HBIG in maintaining anti-HBs titers $>100 \mathrm{IU} / \mathrm{L}$. It was observed that all patients preferred the SC route to the IM route and SC administration of HBIG can effectively maintain anti-HBs levels above the requisite $100 \mathrm{IU} / \mathrm{L}$ while substantially reducing patient discomfort and improving patient satisfaction. ${ }^{99}$ A prospective, observational, 18-week, open-label, singlearm, multicenter study confirmed that self-administering SC HBIG at home achieved high compliance and tolerability in maintenance liver transplant patients. ${ }^{100}$ Thürmann et al investigated pharmacokinetics and safety of a novel $\mathrm{HBIG}$ (Biotest AG) in healthy volunteers after a single SC or IM dose of $30 \mathrm{IU} / \mathrm{kg}$ and observed that the two routes have comparable pharmacokinetic parameters. ${ }^{101}$ Biotest AG launched Zutectra ${ }^{\circledR}$ as a new SC prophylaxis against HBV reinfection in 2010 .

\section{Hydrocortisone}

Hahner et al evaluated the pharmacokinetics and safety of hydrocortisone after SC and IM injection (100 mg) and after $\mathrm{SC}$ administration of sodium chloride $(0.9 \%)$, respectively, at three different visits. Both IM and SC injections increased serum cortisol rapidly and were well tolerated. Regarding the administration route of hydrocortisone, eleven $(91.7 \%)$ patients preferred SC route $(P<0.01)$, whereas one patient did not have any preference. SC administration of $100 \mathrm{mg}$ hydrocortisone shows excellent pharmacokinetics for emergency use with a good safety profile and is preferred by patients over IM injection. ${ }^{102} \mathrm{SC}$ hydrocortisone may become an important new tool to improve the self-management of patients with adrenal insufficiency in the ambulatory setting. Interestingly, a significantly inverse correlation was observed between BMI and $C_{\max }, C_{\mathrm{av}}$, and AUC after SC administration of hydrocortisone, whereas no correlation between BMI and pharmacokinetic data was seen after IM hydrocortisone administration. ${ }^{102}$ The case indicates that patient's BMI should be considered while switching from IM route to SC route.

\section{Morphine}

A prospective randomized double-blind cross-over study compared intermittent IM and SC morphine boluses for postoperative analgesia. Patients received $0.15 \mathrm{mg} / \mathrm{kg}$ of morphine by SC or IM injection. The majority of patients indicated a strong preference for the SC route despite no significant differences in pain scores, respiratory rate, arterial oxygen saturation, heart rate, mean arterial pressure, sedation, or nausea scores between IM and SC administration of morphine. Postoperative analgesia by SC morphine bolus injection is as effective as IM injection with a similar side-effect profile but with greater patient acceptance and less risk. ${ }^{103}$ Double-blind, randomized, cross-over studies compared the pharmacokinetic profiles following a single dose of $2 \mathrm{mg}$ (healthy volunteers) or $5 \mathrm{mg}$ (patients with advanced illness) morphine SC with 150 IU of rHuPH20, SC with $0.9 \%$ normal saline, or IV on three consecutive days. Significantly shorter mean $T_{\max }$ and greater mean $C_{\max }$ were achieved following SC dosing of morphine with rHuPH20 than without rHuPH20, although the extent of exposure of morphine was similar. ${ }^{104,105}$ 


\section{Discussion}

\section{Principles and detailed factors determining the choice of injection route}

Some medications have been observed with the existence of optimal injection route (Table 1). Obviously, it is inappropriate to simply say that one injection route is overwhelmingly better than another route. With respect to insulin and ketamine, there seems to be conflict over whether IV is superior to SC. Statistically significant difference between SC administration and IV administration was observed in efficacy of ketamine for postoperative analgesia in the Javid et al's study (IV > SC) and safety of ketamine for dissociative conscious sedation in the Honarmand et al's study (SC > IV), ${ }^{57,58}$ indicating that the best choice of route for ketamine administration may vary at different clinical circumstances. This can also partly be explained by the fact that the ketamine dose was different between two studies $(0.5 \mathrm{mg} / \mathrm{kg}$ versus $0.6 \mathrm{mg} / \mathrm{kg}$ ) and therefore researchers considered more about side effects (eg, rise in systolic blood pressure and rate-pressure product), given that SC ketamine was as effective as IV ketamine. The belief that insulin delivered by the IV route should act more rapidly and decrease blood glucose levels faster than the SC route has become questionable because continuous $\mathrm{SC}$ insulin infusion using an insulin pump seemed to control the glycemia better compared to IV insulin infusion in medical intensive care unit patients. Bodur et al explained that continuous SC insulin infusion could avoid extra problems brought by IV insulin infusions including 100-fold dilution (50 IU in $50 \mathrm{~mL}$ ) which may bring slight variations in the preparation of the final syringe and change the concentration of insulin considerably, adsorption of insulin to the surface of the syringe and the lines, and sharing the lumens of central catheters where other treatments are streamed with the potential for interference with infusion rates. ${ }^{44} \mathrm{We}$ would like to provide an additional explanation; that is, evidence has shown that continuous SC insulin infusion could significantly reduce the total daily insulin dose and achieve significantly lower incidence of hypoglycemia compared with multiple daily insulin SC injections, ${ }^{106}$ and the studies by Bodur et al and Furnary et al used different protocols (ie, the former study compared continuous IV infusion with continuous SC infusion, whereas the latter study compared continuous IV infusion with sliding-scale-guided intermittent SC insulin injections).

Safety, efficacy, patient preference, and pharmacoeconomics are four principles governing the choice of injection route (Figure 2). Safety and efficacy must be the preferred principles to be considered. Firstly, clinicians should know whether there is a contraindicational route in some cases. Prescribing information for some medications has described the IV, SC, or IM route-related contraindication information. For example, calcium gluconate injection is only for IV use. SC or IM injection may cause severe necrosis and sloughing, and thus, they are contraindicational routes. ${ }^{107}$ The preferred parenteral route of administration for promethazine hydrochloride injection is deep IM injection. SC promethazine is contraindicated as it may result in tissue necrosis. When used intravenously, promethazine hydrochloride injection should be given in concentration no greater than $25 \mathrm{mg} / \mathrm{mL}$ at a rate not to exceed $25 \mathrm{mg} / \mathrm{min}$. ${ }^{108}$ The FDA required a boxed warning for promethazine hydrochloride injection on September 16, 2009, highlighting the risk of serious tissue injury when this drug is administered incorrectly. Norepinephrine bitartrate injection must be diluted in dextrose-containing solutions prior to infusion. Use of IM and SC is contraindicated because of poor absorption and potential local necrosis due to the vasoconstrictive action of the drug. ${ }^{109}$ For methylprednisolone sodium succinate and hydrocortisone sodium succinate, IM administration is contraindicated for treatment of idiopathic thrombocytopenic purpura, and IV is the only injection route for this indication, although the two medications can be given intravenously or intramuscularly for other indications. Chlorpromazine hydrochloride injection is intended for deep IM use. The SC route is contraindicated for chlorpromazine administration to avoid causing skin irritation, while IV route is only for severe hiccups, surgery, and tetanus. Potassium chloride injection must be diluted and infused over a certain period of time. IV push/bolus, SC, and IM are contraindicated routes that would result in the patient receiving too much potassium too quickly.

Second, literature, rather than prescribing information, has provided good suggestions regarding safety and efficacy issue in the choice of injection route. For example, epinephrine should be given intramuscularly during an episode of systemic anaphylaxis, IM morphine should not be given for pain management, and IM redback spider antivenom should not be recommended in the treatment of redback spider bite. If the safety and efficacy of two injection routes are equivalent, clinicians should consider more about patient preference and pharmacoeconomics because patient preference will ensure optimal treatment adherence and ultimately improve patient experience or satisfaction, while pharmacoeconomic concern will help alleviate nurse shortages and reduce overall health care costs. 


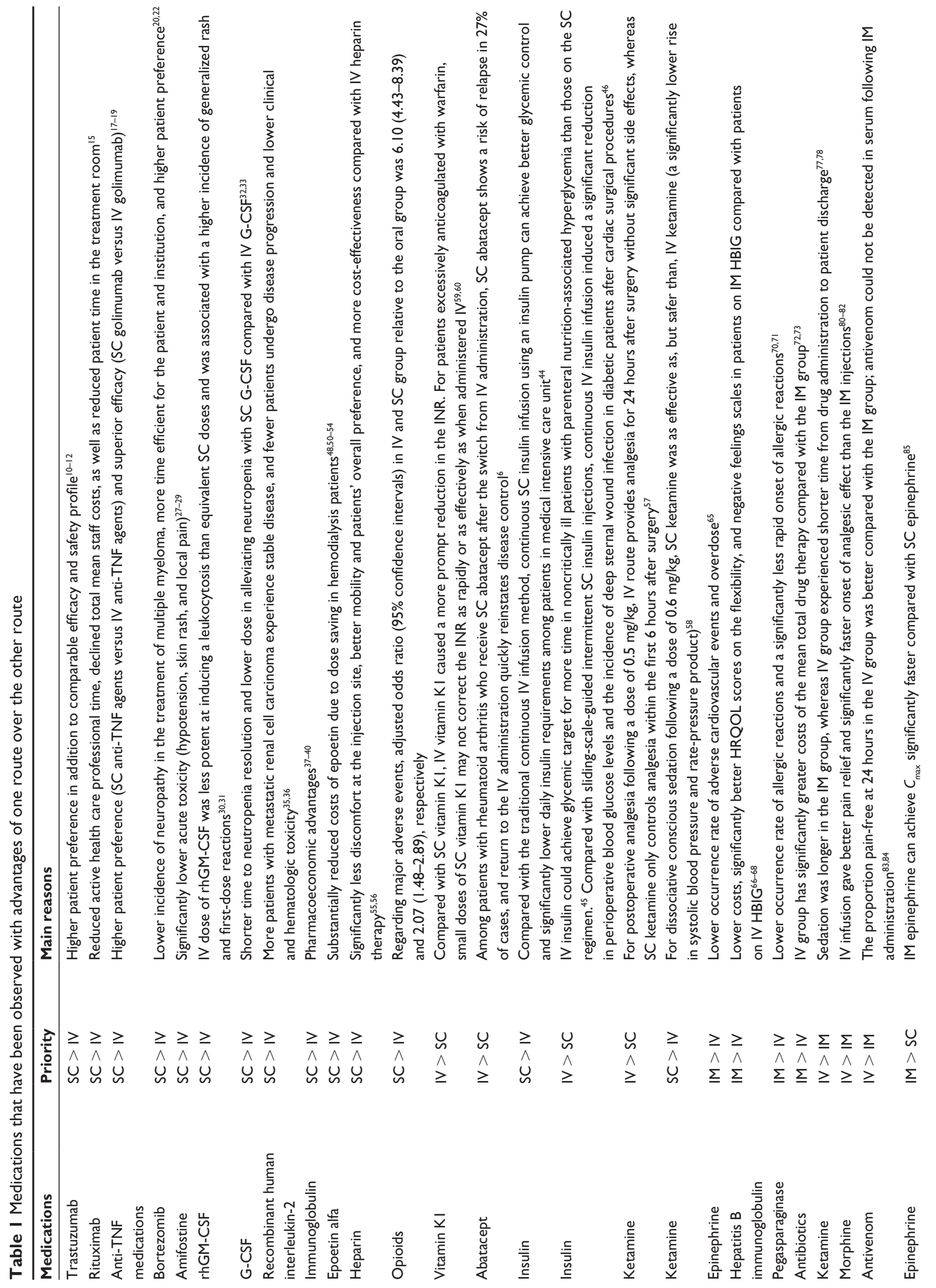


Besides the four principles, the following detailed factors are related with the choice of injection route:

1. Patient characteristics-related factors

- Body mass index (IM versus SC medications [hydrocortisone, $\mathrm{hCG}])^{98,102}$

- Age (SC versus IV medications [ceftriaxone, IG] $)^{41,61}$

- Sex (SC-IG for lifelong treatment of primary antibody deficiencies $)^{42}$

- Medical status (eg, renal impairment [SC versus IV bortezomib], dementia [SC versus IV ceftriaxone] $)^{25,61}$

- Personal attitudes toward safety and convenience, past experience, perception of current disease status (SC versus IV medications [anti-TNF agents, IG] $)^{19,41}$

- Health literacy

- Socioeconomic status (eg, ability to pay)

2. Medication administration-related factors

- Anatomical site of injection (SC bortezomib, IM epinephrine $)^{24,87}$

- Dose (SC versus IV rituximab regarding bioavailability ${ }^{16}$

- Frequency (once-weekly IM IFN $\beta 1$ a had significantly higher regression-adjusted odds of adherence compared with three times weekly SC IFN $\beta 1 \mathrm{a}$ in patients with multiple sclerosis. ${ }^{92}$ Once-weekly SC administration of epoetin beta is as safe and effective in maintaining hemoglobin levels in stable hemodialysis patients as two or three times weekly administration of the same total dose, and would reduce clinic time for patients who do not self-administer, encourage self-administration, and improve overall compliance. ${ }^{110}$ Reducing the dosing frequency of IV Velcade $^{\circledR}$ from twice-weekly to once-weekly significantly reduced severe peripheral neuropathy $(28 \%$ versus $8 \%, P<0.001$ ) but did not affect the efficacy. ${ }^{111}$ Continuous SC insulin infusion is superior to multiple daily insulin SC injections regarding efficacy and incidence of hypoglycemia in Chinese patients with type 2 diabetes mellitus ${ }^{106}$ )

- Formulation characteristics (SC high-concentration MTX versus SC medium-concentration MTX, rHuPH20-facilitated SC trastuzumab versus IV trastuzumab, rHuPH20-facilitated SC-IG versus IV-IG, rHuPH20-facilitated SC ceftriaxone versus SC ceftriaxone) $)^{9,43,62}$

- Administration time (SC versus IV: insulin during pre-, intra-, and postoperative periods $)^{47}$ 


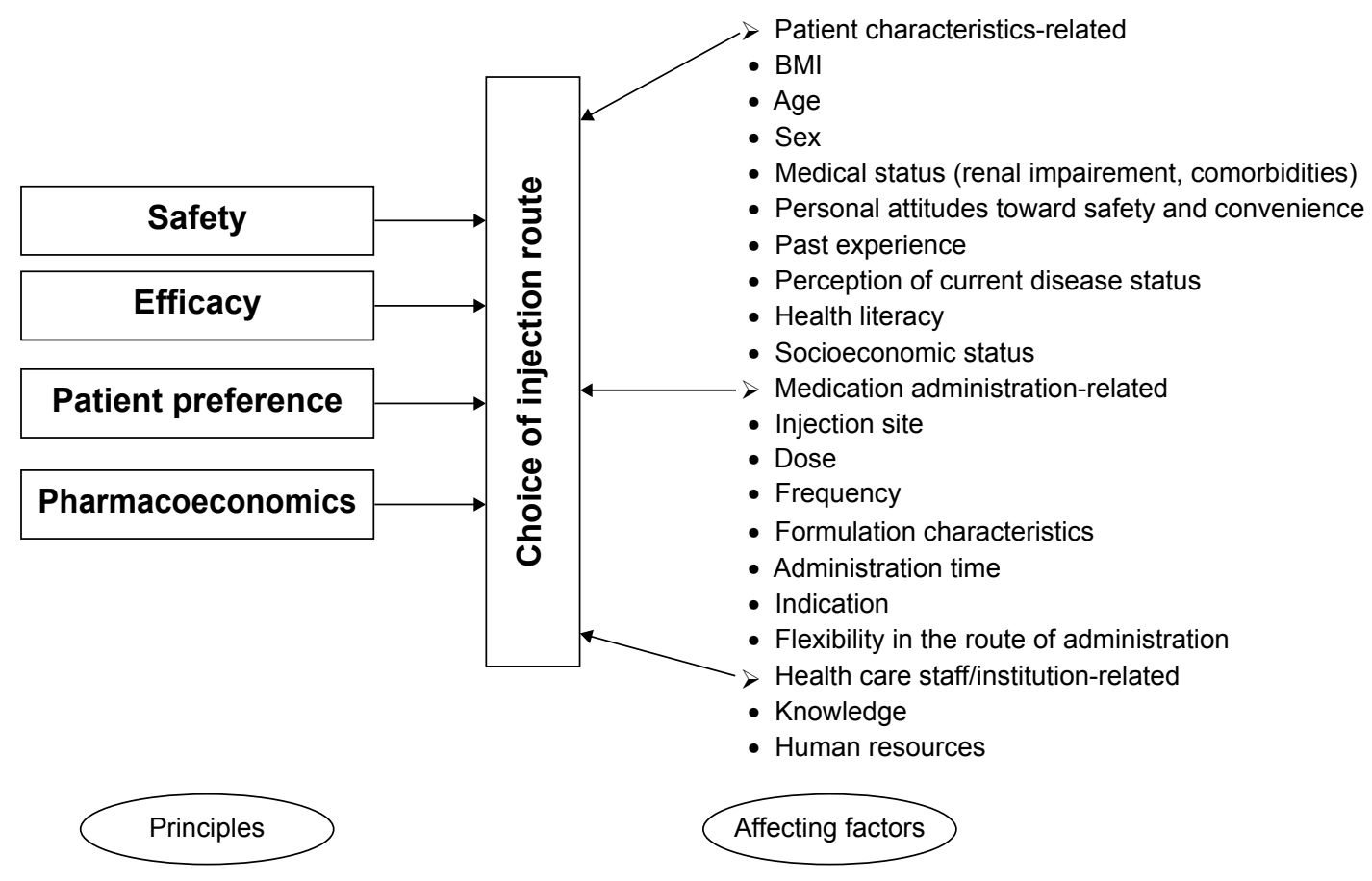

Figure 2 Principles and affecting factors associated with the choice of injection route. Abbreviation: BMI, body mass index.

- Indication (SC versus IV ketamine for different purposes [postoperative analgesia and dissociative conscious sedation] $)^{57,58}$

- Flexibility in the route of administration (eg, among prescribing patterns of morphine including IV-to-oral, IV-to-SC, IV-only, SC-only and mixed mode, the mixed mode achieves the best clinical outcomes) ${ }^{64}$

3. Health care staff-/institution-related factors

- Knowledge (IM epinephrine versus SC or IV epinephrine) ${ }^{85}$

- Human resources (nursing shortages [SC-IG versus IV-IG] $)^{38}$

\section{Further research opportunities}

Further studies are needed. First, it is necessary to conduct prospective intervention studies with multiple outcome measures following a switch to a more appropriate injection route. Second, both retrospective and prospective pharmacoeconomic studies should be encouraged. Third, patient preference is important in medical decision making when choosing treatment methods because it has implications for adherence and quality of life. Therefore, future drug efficacy and safety studies should include contemporaneous, actual patient preference where possible, utilizing appropriate measures. Fourth, it is interesting to evaluate the association of potential determinants with the choice of injection route.
For example, the effect of dosing frequency on the choice of injection route for bortezomib remains to be investigated. In patients with multiple myeloma, once-weekly IV or twice-weekly SC bortezomib has been proven to offer noninferior efficacy and improved safety profile compared with standard twice-weekly IV administration. ${ }^{20,111}$ However, whether once-weekly SC bortezomib has advantages over once-weekly IV bortezomib needs to be validated in future prospective randomized trials.

We did not focus on one point in the form of a Cochrane-style systematic review or meta-analysis because controversial conclusions derived from comparative studies of injection routes are currently rare and our objective is to enrich the knowledge of optimally selecting administration route following a panorama investigation. Some limitations of this review are as follows: First, other databases like EMBASE could not be used due to inaccessibility in the People's Republic of China. Second, we did not include the comparative studies of injection routes without any difference in efficacy, safety, cost, or patient preference, and such exclusion criteria would restrict the vision of advantages brought by $\mathrm{SC}$ administration. For example, even though insignificant difference in safety and efficacy has not been observed when comparing SC route and IV route, SC administration may still be preferred because it is usually more time efficient for the patient and institution. However, 
a new horizon might be opened up by this updated review with plenty of new findings.

\section{Conclusion}

In this updated review, we summarized the findings of comparative studies of different injection routes, which will enrich the knowledge of safe, efficacious, economic, and patient preference-oriented medication administration as well as catching research opportunities in clinical nursing practice. Patients are complex because of biological, medical, socioeconomic, and cultural factors. Personalized therapeutics would go deep into routine practice and improve patient-specific outcomes if clinical practitioners perform comprehensive interventions, such as optimally choosing administration route, dosage and administration consultation services provided by pharmacy, prospective review of the appropriateness of physician orders by pharmacists, and pharmacotherapeutic monitoring following injection therapy.

\section{Acknowledgments}

This work was supported by Zhejiang Provincial Bureau of Education (grant N20140209), Zhejiang Provincial Bureau of Health (grant 2013KYB137), National Major Projects of China grants (2012ZX09506001-004), and National Health and Family Planning Commission of the People's Republic of China (National Key Clinical Discipline Construction: Clinical Nursing Specialist). Also, the authors would like to thank Miss Na Lv, Professor Xiao-na Dai, Mr Sheng-dong Pan, and Miss Xin Huang for their kind help in medication management and use.

\section{Disclosure}

The authors report no conflicts of interest in this work.

\section{References}

1. Injection (Medicine)-WIKIPEDIA, The Free Encyclopedia. [webpage on the Internet] Available from: http://en.wikipedia.org/wiki/ Injection_(medicine). [updated 2015 March 5]. Accessed March 29, 2015.

2. Pharmaceutical drug use principle issued. National Health and Family Planning Commission of China. December 11 2013. Available from: http://news.xinhuanet.com/english/china/2013-12/11/c_132959145.htm. Accessed June 29, 2015

3. Plumb B, Bright P, Gompels MM, Unsworth DJ. Correct recognition and management of anaphylaxis: not much change over a decade. Postgrad Med J. 2015;91:3-7.

4. Gabriel J. Intravenous versus subcutaneous access for palliative care patients. Br J Nurs. 2014;23:S20-S22.

5. Stoner KL, Harder H, Fallowfield LJ, Jenkins VA. Intravenous versus subcutaneous drug administration. which do patients prefer? a systematic review. Patient. Epub 2014 July 12.

6. Reggia R, Franceschini F, Tincani A, Cavazzana I. Switching from intravenous to subcutaneous formulation of abatacept: a single-center Italian experience on efficacy and safety. J Rheumatol. 2015;42:193-195.
7. Dychter SS, Gold DA, Haller MF. Subcutaneous drug delivery: a route to increased safety, patient satisfaction, and reduced costs. J Infus Nurs. 2012;35:154-160.

8. Herceptin. [webpage on the Internet] Available from: http://www.rxlist. com/herceptin-drug/indications-dosage.htm. [updated 2013 May 12] Accessed March 29, 2015.

9. Sanford M. Subcutaneous trastuzumab: a review of its use in HER2positive breast cancer. Target Oncol. 2014;9:85-94.

10. Pivot X, Gligorov J, Müller V, et al; PrefHer Study Group. Patients' preferences for subcutaneous trastuzumab versus conventional intravenous infusion for the adjuvant treatment of HER2-positive early breast cancer: final analysis of 488 patients in the international, randomized, two-cohort PrefHer study. Ann Oncol. 2014;25: 1979-1987.

11. Pivot X, Gligorov J, Müller V, et al; PrefHer Study Group. Preference for subcutaneous or intravenous administration of trastuzumab in patients with HER2-positive early breast cancer (PrefHer): an openlabel randomised study. Lancet Oncol. 2013;14:962-970.

12. Jackisch C, Kim SB, Semiglazov V, et al. Subcutaneous versus intravenous formulation of trastuzumab for HER2-positive early breast cancer: updated results from the phase III HannaH study. Ann Oncol. 2015;26:320-325.

13. RITUXAN. [webpage on the Internet] Available from: http://www.rxlist. com/rituxan-drug/indications-dosage.htm. [updated 2013 October 21] Accessed March 29, 2015.

14. Salar A, Avivi I, Bittner B, et al. Comparison of subcutaneous versus intravenous administration of rituximab as maintenance treatment for follicular lymphoma: results from a two-stage, phase IB study. J Clin Oncol. 2014;32:1782-1791.

15. Rule S, Collins GP, Samanta K. Subcutaneous vs intravenous rituximab in patients with non-Hodgkin lymphoma: a time and motion study in the United Kingdom. J Med Econ. 2014;17:459-468.

16. Kagan L, Turner MR, Balu-Iyer SV, Mager DE. Subcutaneous absorption of monoclonal antibodies: role of dose, site of injection, and injection volume on rituximab pharmacokinetics in rats. Pharm Res. 2012;29:490-499.

17. Doyle MK, Rahman MU, Frederick B, et al. Effects of subcutaneous and intravenous golimumab on inflammatory biomarkers in patients with rheumatoid arthritis: results of a phase 1, randomized, open-label trial. Rheumatology (Oxford). 2013;52:1214-1219.

18. Sylwestrzak G, Liu J, Stephenson JJ, Ruggieri AP, DeVries A. Considering patient preferences when selecting anti-tumor necrosis factor therapeutic options. Am Health Drug Benefits. 2014;7: $71-81$.

19. Scarpato S, Antivalle M, Favalli EG, et al; RIVIERA co-authors. Patient preferences in the choice of anti-TNF therapies in rheumatoid arthritis. Results from a questionnaire survey (RIVIERA study). Rheumatology (Oxford). 2010;49:289-294.

20. Moreau P, Pylypenko H, Grosicki S, et al. Subcutaneous versus intravenous administration of bortezomib in patients with relapsed multiple myeloma: a randomised, phase 3, non-inferiority study. Lancet Oncol. 2011;12:431-440.

21. Moreau P, Karamanesht II, Domnikova N, et al. Pharmacokinetic, pharmacodynamic and covariate analysis of subcutaneous versus intravenous administration of bortezomib in patients with relapsed multiple myeloma. Clin Pharmacokinet. 2012;51:823-829.

22. Arnulf B, Pylypenko H, Grosicki S, et al. Updated survival analysis of a randomized phase III study of subcutaneous versus intravenous bortezomib in patients with relapsed multiple myeloma. Haematologica. 2012;97:1925-1928

23. Barbee MS, Harvey RD, Lonial S, et al. Subcutaneous versus intravenous bortezomib: efficiency practice variables and patient preferences. Ann Pharmacother. 2013;47:1136-1142.

24. Kamimura T, Miyamoto T, Yokota N, Aoki T, Ito Y, Akashi K. High incidence and severity of injection site reactions in the first cycle compared with subsequent cycles of subcutaneous bortezomib. Int $J$ Hematol. 2013;98:694-701. 
25. Moreau P, Pylypenko H, Grosicki S, et al. Subcutaneous versus intravenous bortezomib in patients with relapsed multiple myeloma: subanalysis of patients with renal impairment in the phase III MMY3021 study. Haematologica. 2015;100(5):e207-e210.

26. Ethyol. [webpage on the Internet] Available from: http://www.rxlist.com/ ethyol-drug.htm. [updated 2008 August 18]. Accessed March 29, 2015.

27. Bardet E, Martin L, Calais G, et al. Subcutaneous compared with intravenous administration of amifostine in patients with head and neck cancer receiving radiotherapy: final results of the GORTEC 2000-2002 phase III randomized trial. J Clin Oncol. 2011;29:127-133.

28. Koukourakis MI, Simopoulos C, Minopoulos G, et al. Amifostine before chemotherapy: improved tolerance profile of the subcutaneous over the intravenous route. Clin Cancer Res. 2003;9:3288-3293.

29. Bardet E, Martin L, Calais G, et al. Preliminary data of the GORTEC 2000-2002 phase III trial comparing intravenous and subcutaneous administration of amifostine for head and neck tumors treated by external radiotherapy. Semin Oncol. 2002;29(6 suppl 19):57-60.

30. Rosenfeld CS, Sulecki M, Evans C, Shadduck RK. Comparison of intravenous versus subcutaneous recombinant human granulocytemacrophage colony-stimulating factor in patients with primary myelodysplasia. Exp Hematol. 1991;19:273-277.

31. Lieschke GJ, Maher D, O'Connor M, et al. Phase I study of intravenously administered bacterially synthesized granulocyte-macrophage colony-stimulating factor and comparison with subcutaneous administration. Cancer Res. 1990;50:606-614.

32. Paul M, Ram R, Kugler E, et al. Subcutaneous versus intravenous granulocyte colony stimulating factor for the treatment of neutropenia in hospitalized hemato-oncological patients: randomized controlled trial. Am J Hematol. 2014;89:243-248.

33. Eguchi K, Shinkai T, Sasaki Y, et al. Subcutaneous administration of recombinant human granulocyte colony-stimulating factor (KRN8601) in intensive chemotherapy for patients with advanced lung cancer. Jpn J Cancer Res. 1990;81:1168-1174.

34. Interleukin 2. [webpage on the Internet] Available from: http:// en.wikipedia.org/wiki/Interleukin_2. [updated 2015 January 26]. Accessed March 29, 2015.

35. Geertsen PF, Gore ME, Negrier S, Tourani JM, von der Maase H. Safety and efficacy of subcutaneous and continuous intravenous infusion rIL-2 in patients with metastatic renal cell carcinoma. Br J Cancer. 2004;90:1156-1162.

36. López-Jiménez J, Pérez-Oteyza J, Munoz A, et al. Subcutaneous versus intravenous low-dose IL-2 therapy after autologous transplantation: results of a prospective, non-randomized study. Bone Marrow Transplant. 1997; 19:429-434.

37. Gerth WC, Betschel SD, Zbrozek AS. Implications to payers of switch from hospital-based intravenous immunoglobulin to home-based subcutaneous immunoglobulin therapy in patients with primary and secondary immunodeficiencies in Canada. Allergy Asthma Clin Immunol. 2014;10:23.

38. Martin A, Lavoie L, Goetghebeur M, Schellenberg R. Economic benefits of subcutaneous rapid push versus intravenous immunoglobulin infusion therapy in adult patients with primary immune deficiency. Transfus Med. 2013;23:55-60.

39. Abolhassani H, Sadaghiani MS, Aghamohammadi A, Ochs HD, Rezaei N. Home-based subcutaneous immunoglobulin versus hospital-based intravenous immunoglobulin in treatment of primary antibody deficiencies: systematic review and meta analysis. J Clin Immunol. 2012;32:1180-1192.

40. Ducruet T, Levasseur MC, Des Roches A, Kafal A, Dicaire R, Haddad E. Pharmacoeconomic advantages of subcutaneous versus intravenous immunoglobulin treatment in a Canadian pediatric center. J Allergy Clin Immunol. 2013;131:e1-e3.

41. Kittner JM, Grimbacher B, Wulff W, Jäger B, Schmidt RE. Patients' attitude to subcutaneous immunoglobulin substitution as home therapy. J Clin Immunol. 2006;26:400-405.

42. Gardulf A, Björvell H, Andersen V, et al. Lifelong treatment with gammaglobulin for primary antibody deficiencies: the patients' experiences of subcutaneous self-infusions and home therapy. J Adv Nurs. $1995 ; 21: 917-927$.
43. Wasserman RL, Melamed I, Stein MR, et al; IGSC, $10 \%$ with $\mathrm{rHuPH} 20$ Study Group. Recombinant human hyaluronidase-facilitated subcutaneous infusion of human immunoglobulins for primary immunodeficiency. J Allergy Clin Immunol. 2012;130:951.e-957.e.

44. Bodur HA, Saygili F, Saygili S, Doganay LH, Yesil S. Continuous infusion of subcutaneous compared to intravenous insulin for tight glycaemic control in medical intensive care unit patients. Anaesth Intensive Care. 2008;36:520-527.

45. Neff K, Donegan D, MacMahon J, et al. Management of parenteral nutrition associated hyperglycaemia: a comparison of subcutaneous and intravenous insulin regimen. Ir Med J. 2014;107:141-143.

46. Furnary AP, Zerr KJ, Grunkemeier GL, Starr A. Continuous intravenous insulin infusion reduces the incidence of deep sternal wound infection in diabetic patients after cardiac surgical procedures. Ann Thorac Surg. 1999;67:352-360.

47. Pezzarossa A, Taddei F, Cimicchi MC, et al. Perioperative management of diabetic subjects. Subcutaneous versus intravenous insulin administration during glucose-potassium infusion. Diabetes Care. 1988;11:52-58.

48. Wazny LD, Raymond CB, Sood AR, Eng A, Verrelli M. Cost analysis of an intravenous to subcutaneous epoetin $\alpha$ conversion. Am J Nephrol. 2013;38:496-500

49. Besarab A, Reyes CM, Hornberger J. Meta-analysis of subcutaneous versus intravenous epoetin in maintenance treatment of anemia in hemodialysis patients. Am J Kidney Dis. 2002;40:439-446.

50. Albitar S, Meulders Q, Hammoud H, Soutif C, Bouvier P, Pollini J. Subcutaneous versus intravenous administration of erythropoietin improves its efficiency for the treatment of anaemia in haemodialysis patients. Nephrol Dial Transplant. 1995;10(suppl 6):40-43.

51. McFarlane PA, Hillmer MP, Dacouris N. A change from subcutaneous to intravenous erythropoietin increases the cost of anemia therapy. Nephron Clin Pract. 2007;107:c90-c96.

52. Vercaigne LM, Collins DM, Penner SB. Conversion from subcutaneous to intravenous erythropoietin in a hemodialysis population. J Clin Pharmacol. 2005;45:895-900.

53. Raymond CB, Collins DM, Bernstein KN, Skwarchuk DE, Vercaigne LM. Erythropoietin-alpha dosage requirements in a provincial hemodialysis population: effect of switching from subcutaneous to intravenous administration. Nephron Clin Pract. 2006;102:c88-c92.

54. Galliford JW, Malasana R, Farrington K. Switching from subcutaneous to intravenous erythropoietin alpha in haemodialysis patients requires a major dose increase. Nephrol Dial Transplant. 2005;20: 1956-1962.

55. Robinson AM, McLean KA, Greaves M, Channer KS. Subcutaneous versus intravenous administration of heparin in the treatment of deep vein thrombosis; which do patients prefer? A randomized cross-over study. Postgrad Med J. 1993;69:115-116.

56. Barber ND, Hoffmeyer UK. Comparison of the cost-effectiveness of administering heparin subcutaneously or intravenously for the treatment of deep vein thrombosis. Ann R Coll Surg Engl. 1993;75:430-433.

57. Honarmand A, Safavi M, Karaky H. Preincisional administration of intravenous or subcutaneous infiltration of low-dose ketamine suppresses postoperative pain after appendectomy. J Pain Res. 2012;5: $1-6$.

58. Javid MJ, Rahimi M, Keshvari A. Dissociative conscious sedation, an alternative to general anesthesia for laparoscopic peritoneal dialysis catheter implantation: a randomized trial comparing intravenous and subcutaneous ketamine. Perit Dial Int. 2011;31:308-314.

59. Raj G, Kumar R, McKinney WP. Time course of reversal of anticoagulant effect of warfarin by intravenous and subcutaneous phytonadione. Arch Intern Med. 1999;159:2721-2724.

60. Nee R, Doppenschmidt D, Donovan DJ, Andrews TC. Intravenous versus subcutaneous vitamin $\mathrm{K} 1$ in reversing excessive oral anticoagulation. Am J Cardiol. 1999;83(286-288):A6-A7.

61. Gauthier D, Schambach S, Crouzet J, Sirvain S, Fraisse T. Subcutaneous and intravenous ceftriaxone administration in patients more than 75 years of age. Med Mal Infect. 2014;44:275-280. 
62. Harb G, Lebel F, Battikha J, Thackara JW. Safety and pharmacokinetics of subcutaneous ceftriaxone administered with or without recombinant human hyaluronidase ( $\mathrm{rHuPH} 20$ ) versus intravenous ceftriaxone administration in adult volunteers. Curr Med Res Opin. 2010;26: 279-288.

63. Daoust R, Paquet J, Lavigne G, Piette É, Chauny JM. Impact of age, sex and route of administration on adverse events after opioid treatment in the emergency department: a retrospective study. Pain Res Manag. 2015;20:23-28.

64. Walsh D, Perin ML, McIver B. Parenteral morphine prescribing patterns among inpatients with pain from advanced cancer: a prospective survey of intravenous and subcutaneous use. Am J Hosp Palliat Care. 2006;23:353-359.

65. Campbell RL, Bellolio MF, Knutson BD, et al. Epinephrine in anaphylaxis: higher risk of cardiovascular complications and overdose after administration of intravenous bolus epinephrine compared with intramuscular epinephrine. J Allergy Clin Immunol Pract. 2015;3:76-80.

66. Faust D, Rabenau HF, Allwinn R, Caspary WF, Zeuzem S. Costeffective and safe ambulatory long-term immunoprophylaxis with intramuscular instead of intravenous hepatitis B immunoglobulin to prevent reinfection after orthotopic liver transplantation. Clin Transplant. 2003;17:254-258.

67. Han SH, Martin P, Edelstein M, et al. Conversion from intravenous to intramuscular hepatitis B immune globulin in combination with lamivudine is safe and cost-effective in patients receiving long-term prophylaxis to prevent hepatitis B recurrence after liver transplantation. Liver Transpl. 2003;9:182-187.

68. Franciosi M, Caccamo L, De Simone P, et al; TWINS I Study Group. Development and validation of a questionnaire evaluating the impact of hepatitis B immune globulin prophylaxis on the quality of life of liver transplant recipients. Liver Transpl. 2012;18:332-339.

69. Oncaspar. [webpage on the Internet] Available from: http://www.rxlist. com/oncaspar-drug.htm. [updated 2014 May 2]. Accessed March 29, 2015.

70. Pidaparti M, Bostrom B. Comparison of allergic reactions to pegasparaginase given intravenously versus intramuscularly. Pediatr Blood Cancer. 2012;59:436-439.

71. Petersen WC Jr, Clark D, Senn SL, et al. Comparison of allergic reactions to intravenous and intramuscular pegaspargase in children with acute lymphoblastic leukemia. Pediatr Hematol Oncol. 2014;31:311-317.

72. Milkovich G, Piazza CJ. Considerations in comparing intravenous and intramuscular antibiotics. Chemotherapy. 1991;37(suppl 2):1-13.

73. Chin A, Gill MA, Ito MK, et al. A cost comparison of intramuscular versus intravenous imipenem. Hosp Pharm. 1989;24:905-909.

74. Radwanski E, Batra V, Cayen M, et al. Pharmacokinetics of isepamicin following a single administration by intravenous infusion or intramuscular injections. Antimicrob Agents Chemother. 1997;41: 1794-1796.

75. Antony KK, Lewis EW, Kenny MT, et al. Pharmacokinetics and bioavailability of a new formulation of teicoplanin following intravenous and intramuscular administration to humans. J Pharm Sci. 1991;80:605-607.

76. Goonetilleke AK, Dev D, Aziz I, Hughes C, Smith MJ, Basran GS. A comparative analysis of pharmacokinetics of ceftriaxone in serum and pleural fluid in humans: a study of once daily administration by intramuscular and intravenous routes. J Antimicrob Chemother. 1996;38:969-976.

77. Momeni M, Esfandbod M, Saeedi M, Farnia M, Basirani R, Zebardast J. Comparison of the effect of intravenous ketamine and intramuscular ketamine for orthopedic procedures in children's sedation. Int J Crit Illn Inj Sci. 2014;4:191-194.

78. Ramaswamy P, Babl FE, Deasy C, Sharwood LN. Pediatric procedural sedation with ketamine: time to discharge after intramuscular versus intravenous administration. Acad Emerg Med. 2009;16:101-107.

79. Roback MG, Wathen JE, MacKenzie T, Bajaj L. A randomized, controlled trial of i.v. versus i.m. ketamine for sedation of pediatric patients receiving emergency department orthopedic procedures. Ann Emerg Med. 2006;48:605-612.
80. Dale O, Thoner J, Nilsen T, Tveita T, Borchgrevink PC, Klepstad P Serum and cerebrospinal fluid morphine pharmacokinetics after single doses of intravenous and intramuscular morphine after hip replacement surgery. Eur J Clin Pharmacol. 2007;63:837-842.

81. Tveita T, Thoner J, Klepstad P, Dale O, Jystad A, Borchgrevink PC. A controlled comparison between single doses of intravenous and intramuscular morphine with respect to analgesic effects and patient safety. Acta Anaesthesiol Scand. 2008;52:920-925.

82. Hendrickson M, Myre L, Johnson DG, Matlak ME, Black RE, Sullivan JJ. Postoperative analgesia in children: a prospective study in intermittent intramuscular injection versus continuous intravenous infusion of morphine. J Pediatr Surg. 1990;25:185-190.

83. Ellis RM, Sprivulis PC, Jelinek GA, et al. A double-blind, randomized trial of intravenous versus intramuscular antivenom for red-back spider envenoming. Emerg Med Australas. 2005;17:152-156.

84. Isbister GK, O'Leary M, Miller M, et al. A comparison of serum antivenom concentrations after intravenous and intramuscular administration of redback (widow) spider antivenom. Br J Clin Pharmacol. 2008;65:139-143.

85. Simons FE, Roberts JR, Gu X, Simons KJ. Epinephrine absorption in children with a history of anaphylaxis. J Allergy Clin Immunol. 1998;101: 33-37.

86. Haymore BR, Carr WW, Frank WT. Anaphylaxis and epinephrine prescribing patterns in a military hospital: underutilization of the intramuscular route. Allergy Asthma Proc. 2005;26:361-365.

87. Simons FE, Gu X, Simons KJ. Epinephrine absorption in adults: intramuscular versus subcutaneous injection. J Allergy Clin Immunol. 2001;108:871-873.

88. REBIF. [webpage on the Internet] Available from: http://www.rxlist. com/rebif-drug/indications-dosage.htm. [updated 2014 May 12]. Accessed March 29, 2015.

89. AVONEX ${ }^{\circledR}$. [webpage on the Internet] Available from: http://www.rxlist. com/avonex-drug/indications-dosage.htm. [updated 2013 March 27] Accessed March 29, 2015

90. Guo S, Bozkaya D, Ward A, et al. Treating relapsing multiple sclerosis with subcutaneous versus intramuscular interferon-beta-1a: modelling the clinical and economic implications. Pharmacoeconomics. 2009;27:39-53.

91. Calabrese M, Bernardi V, Atzori M, et al. Effect of disease-modifying drugs on cortical lesions and atrophy in relapsing-remitting multiple sclerosis. Mult Scler. 2012;18:418-424.

92. Halpern R, Agarwal S, Dembek C, Borton L, Lopez-Bresnahan M. Comparison of adherence and persistence among multiple sclerosis patients treated with disease-modifying therapies: a retrospective administrative claims analysis. Patient Prefer Adherence. 2011;5:73-84.

93. Brooks PJ, Spruill WJ, Parish RC, Birchmore DA. Pharmacokinetics of methotrexate administered by intramuscular and subcutaneous injections in patients with rheumatoid arthritis. Arthritis Rheum. 1990;33:91-94.

94. Jundt JW, Browne BA, Fiocco GP, Steele AD, Mock D. A comparison of low dose methotrexate bioavailability: oral solution, oral tablet, subcutaneous and intramuscular dosing. J Rheumatol. 1993;20(11): 1845-1849.

95. Arthur V, Jubb R, Homer D. A study of parenteral use of methotrexate in rheumatic conditions. J Clin Nurs. 2002;11:256-263.

96. Müller-Ladner U, Rockwitz K, Brandt-Jürgens J, et al; MC-MTX.10/ RH Study Group. Tolerability and patient/physician satisfaction with subcutaneously administered methotrexate provided in two formulations of different drug concentrations in patients with rheumatoid arthritis Open Rheumatol J. 2010;4:15-22.

97. Stelling JR, Chapman ET, Frankfurter D, Harris DH, Oskowitz SP, Reindollar RH. Subcutaneous versus intramuscular administration of human chorionic gonadotropin during an in vitro fertilization cycle. Fertil Steril. 2003;79:881-885.

98. Shah DK, Missmer SA, Correia KF, Ginsburg ES. Pharmacokinetics of human chorionic gonadotropin injection in obese and normal-weight women. J Clin Endocrinol Metab. 2014;99:1314-1321. 
99. Singham J, Greanya ED, Lau K, Erb SR, Partovi N, Yoshida EM. Efficacy of maintenance subcutaneous hepatitis B immune globulin (HBIG) post-transplant for prophylaxis against hepatitis B recurrence. Ann Hepatol. 2010;9:166-171.

100. Klein CG, Cicinnati V, Schmidt H, et al. Compliance and tolerability of subcutaneous hepatitis B immunoglobulin self-administration in liver transplant patients: a prospective, observational, multicenter study. Ann Transplant. 2013;18:677-684.

101. Thürmann PA, Szymanski J, Haffner S, Tenter U, Grieger F, Sonnenburg C. Pharmacokinetics and safety of a novel anti-HBsenriched immunoglobulin in healthy volunteers after subcutaneous and intramuscular administration. Eur J Clin Pharmacol. 2006; 62:511-512.

102. Hahner S, Burger-Stritt S, Allolio B. Subcutaneous hydrocortisone administration for emergency use in adrenal insufficiency. Eur $J$ Endocrinol. 2013;169:147-154.

103. Cooper IM. Morphine for postoperative analgesia. A comparison of intramuscular and subcutaneous routes of administration. Anaesth Intensive Care. 1996;24:574-578.

104. Thomas JR, Yocum RC, Haller MF, Flament J. The INFUSE-morphine IIB study: use of recombinant human hyaluronidase (rHuPH20) to enhance the absorption of subcutaneous morphine in healthy volunteers. J Pain Symptom Manage. 2009;38:673-682.

105. Thomas JR, Wallace MS, Yocum RC, Vaughn DE, Haller MF, Flament J. The INFUSE-Morphine study: use of recombinant human hyaluronidase (rHuPH20) to enhance the absorption of subcutaneously administered morphine in patients with advanced illness. J Pain Symptom Manage. 2009;38:663-672.
106. Yang H, Heng X, Liang C, et al. Comparison of continuous subcutaneous insulin infusion and multiple daily insulin injections in Chinese patients with type 2 diabetes mellitus. J Int Med Res. 2014;42: 1002-1010.

107. Calcium gluconate injection. [webpage on the Internet] Available from: http://www.rxlist.com/calcium-gluconate-drug.htm. [updated 2009 April 2]. Accessed May 1, 2015.

108. Promethazine hydrochloride injection. [webpage on the Internet] Available from: http://www.rxlist.com/promethazine-hcl-injection-drug/ indications-dosage.htm. [updated 2007 June 21]. Accessed May 1, 2015.

109. Norepinephrine bitartrate injection. [webpage on the Internet] Available from: http://www.rxlist.com/levophed-drug/warnings-precautions. htm. [updated 2012 December 2]. Accessed May 1, 2015.

110. Weiss LG, Clyne N, Divino Fihlho J, Frisenette-Fich C, Kurkus J, Svensson B. The efficacy of once weekly compared with two or three times weekly subcutaneous epoetin beta: results from a randomized controlled multicentre trial. Swedish Study Group. Nephrol Dial Transplant. 2000;15:2014-2019.

111. Bringhen S, Larocca A, Rossi D, et al. Efficacy and safety of onceweekly bortezomib in multiple myeloma patients. Blood. 2010; 116:4745-4753.
Patient Preference and Adherence

\section{Publish your work in this journal}

Patient Preference and Adherence is an international, peer-reviewed, open access journal that focuses on the growing importance of patient preference and adherence throughout the therapeutic continuum. Patient satisfaction, acceptability, quality of life, compliance, persistence and their role in developing new therapeutic modalities and compounds to optimize

\section{Dovepress}

clinical outcomes for existing disease states are major areas of interest for the journal. This journal has been accepted for indexing on PubMed Central. The manuscript management system is completely online and includes a very quick and fair peer-review system, which is all easy to use. Visit http://www. dovepress.com/testimonials.php to read real quotes from published authors. 